MUZIKOLOŠKI ZBORNIK - MUSICOLOGICAL ANNUAL IX, LJUBLJANA 1973

UDK 78.034 .8

\title{
ZUM BEGRIFF DES ROKOKOSTILS IN DER MUSIK
}

\author{
Rudolf P e čman (Brno)
}

Das neuere musikwissenschaftliche Schrifttum ${ }^{1}$ faßt das Rokoko in der Musik als echten Úbergangsstil auf, der dem Barock folgt, wie etwa die bildende Kunst. Das Rokoko vereinfacht und zügelt die Ausdrucksmittel der Musik, es gefällt sich in preziöser Schlichtheit, in der Klärung der Tonsprache, und liebt die Homophonie mehr als die Polyphonie. Schon H. H. Eggebrecht hat unterstrichen, ${ }^{2}$ daß das eigentliche Rokoko in der Musik relativ kurz war und bald in die sogenannte empfindsame Phase des Zeitstils überging, der mit dem Sturm und Drang korrespondierte. Von hier aus führt dann der Weg zu den Jahren der gipfelnden Klassik eines Joseph Haydn, Wolfgang Amadeus Mozart und Ludwig van Beethoven. Im ganzen gesehen erscheint also der "galante« Stil in der Musik als Vorläufer der Hochklassik, bleibt aber anderseits historischer Bestandteil des Barocks. In diesem Zusammenhang wäre noch $\mathrm{zu}$ betonen, daß man keine strenge Grenze zwischen dem kurzen Zeitabschnitt des echten Rokokos und der bildlich Sturm und Drang genannten Periode ziehen kann. Diese beiden kurzen Stilperioden durchdringen einander und münden schließlich unmittelbar in die Klassik. Übrigens läßt sich bisher nicht einmal die Dauer des Rokokos in der Musik genau begrenzen. Man behilft sich damit, diesen Stil mit dem Rokoko in den bildenden Künsten zu identifizieren und offenkundige Parallelen zu konstatieren: "Der ,galante' Stil wird häufig als eine Art Nachspiel zum Barock betrachtet und dem Rokoko der bildenden Künste gleichgesetzt. Die Parallele liegt nahe, weil in den dekorativen Künsten und der Malerei des Rokoko eine ähnlich verspielte Grazie, ein ähnliches ,sfumato', eine ähnlich schmachtende Zärtlichkeit, aber auch eine ähnliche Ironie und Melancholie anzutreffen sind wie in mancher musikalischen Komposition des galanten Stils, besonders seiner empfindsamen Phase. Aber abgesehen davon, daß sie sich aus chro-

${ }^{1}$ Vgl. hauptsächlich: Bücken, Gerber, Eggebrecht, Hoffmann-Erbrecht, Pečman I, Pečman II, Blume I.

2 Eggebrecht, $323 \mathrm{f}$. 
nologischen Gründen kaum aufrechterhalten läßt, wird hierbei übersehen, daß die Formen des Rokoko in den bildenden Künsten unmittelbar aus den Spätformen des Barock hervorgegangen sind, während in der Musik der galante Stil jenseits der Kluft steht, die das jüngere Zeitalter von dem älteren trennt: die absichtsvolle Beschränkung der Mittel, die preziöse Schlichtheit und der Vorrang der nur beiläufig begleiteten einstimmigen Melodie lassen erkennen, daß im galanten Stil weit eher ein klassisches als ein barockes Grundgefühl waltet." Diese treffende Charakteristik Friedrich Blumes $^{3}$ knüpft vor allem an Bückens und Gerbers ${ }^{4}$ Auffassung an: als "rokokomäßig" gilt das, was dem »Klassischen" (im engeren Wortsinn) vorangeht. Als Vorgänger der Hochklassik haben demnach einerseits der höfische, galante Stil, anderseits der empfindsame Stil $\mathrm{zu}$ gelten. Im tschechischen musikwissenschaftlichen Kontext ist diese Terminologie nicht einmal üblich. Sofern man hier überhaupt von so feinen Stilschattierungen spricht, greift man zu Ausdrücken, die aus der deutschen Musikwissenschaft entlehnt sind ("galanter" Stil, »empfindsamer" Stil). Noch häufiger verwechselt man (aus Unkenntnis der Sache) pars pro toto und stellt ein vereinfachendes Gleichkeitszeichen zwischen die Begriffe "galant« und "rokokomäßig". Das ist natürlich höchst zweifelhalt, weil der Begriff "Rokoko« beiden Begriffen übergeordnet und mit keinem von ihnen identisch ist. Identität herrscht nicht einmal zwischen den Begriffen "galant« und »empfindsam", weil es sich hier um Bezeichnung zweier Entwicklungsphasen des Rokokos handelt, die aneinander anknüpfen: als "höfisch" oder "galant" hat jener Stil zu gelten, der sich noch im Schoße des Barocks entwickelt, in seiner letzten Entwicklungsphase wächst und um das Jahr 1740 kulminiert; von den vierziger Jahren des 18. Jahrhunderts an müßte man schon vom »empfindsamen « Stil sprechen, der sich zeitlich mit der Periode der Geburt und Entwicklung der vorklassischen Symphonie deckt und unmittelbar in den Stil der Klassik mündet. Um die fünfziger Jahre beginnt sich jener »empfindsame « Stil der Musik, den das subjektiv Ausdrucksvolle charakterisiert, zum klassischen Stil zu wandeln, als dessen Bahnbrecher bereits Carl Philipp Emanuel Bach, Christoph Willibald Gluck, von den Italiener beispielsweise Tartini, Nardini, Boccherini und Cimarosa zu gelten haben, deren Schaffen sich zeitlich mit dem Wirken der beiden großen Wiener Klassiker Joseph Haydn und Wolfgang Amadeus Mozart deckt.

Der Kulturhistoriker Casimir von Chłędowski stellte bereits vor Jahren in seiner Arbeit über das Rokoko in Italien heraus, ${ }^{5}$ daß gerade dieses Land die Priorität der Formung des Rokokos besitzt: »Die eigentliche Heimat des Rokoko war Italien, und wenn später die Form der Perücken und der Schnitt der Kleider aus Paris nach Venedig und Rom gekommen ist, so darf man deshalb die Ur-

3 Blume I, 142.

4 Vgl. Anm. 1.

5 Chłı̨dowski, 3. 
sprünge der Kultur des Rokoko nicht in Frankreich suchen. (...) Im 18. Jahrhundert hat die Seinestadt das italienische Rokoko auf ihre Art verändert und die entlehnten Formen gelegentlich dem Mutterland, reicher und schöner ausgestaltet, wiedergegeben."Versuchen wir nun, diese These Chłędowskis vom Standpunkt der Stilanalyse auch auf dem Gebiet der Musik zu unterstützen.

Die auf eine Stilwandlung hinweisenden Tendenzen sind im musikalischen Italien des 18. Jahrhunderts latent vorhanden, melden sich jedoch hier und da, eigentlich bereits seit Beginn dieses Jahrhunderts, auch deutlicher zu Worte. Am markantesten treten sie auf dem Felde der Instrumentalmusik und im Habitus der Melodik zutage. Spuren des galanten Stils findet man in Italien recht früh. Zum Unterschied von Ernst Bücken ${ }^{6}$ nehmen wir an, daß einer der ausgesprochenen Vorläufer dieses Stils bereits Arcangelo Corelli (1653 bis 1713$)^{7}$ gewesen ist, dessen Instrumentalschaffen sich $\mathrm{zu}$ einer Zeit entfaltete, als die Instrumentalformen und Ausdrucksmittel der Italienischen Musik des sogenannten Hochbarocks zum Kanon geworden waren. Dieses Schaffen bietet Belege für unsere Meinung, daß in der Musik Italiens auf die Klassik zielende Elemente bereits zu einer Zeit erscheinen, die wir gewohnt sind, noch kurz und bündig als »barock« zu bezeichnen. Und gerade Corellis Musik enthält solche Elemente, die weder mit dem ernsten kontrapunktischen Stil der vorhergehenden Zeit, noch mit der profunden Polyphonie deutscher Prägung ${ }^{8}$ zusammenhängen und eine Klärung des Ausdrucks noch früher signalisieren als in der neapolitanischen opera seria. Corelli pflegt nicht nur die Solosonate mit beziffertem Baß, sondern auch die Triosonate und vor allem das sogenannte concerto grosso. Er ist allerdings nicht der Gründer dieser Form, obwohl er zu ihrem ureigensten Vollender wird.

Auf den Terminus concerto grosso stoßen wir zum ersten Mal bei den Intermedien des Christophan Malvezzi (1547-1597), die aus dem Jahr 1591 stammen. Der Begriff concerto grosso bedeutet allerdings bei Malvezzi den simultanen Einsatz aller Instrumente und deckt sich also mehr oder weniger mit dem späteren tutti. Die Anfänge diseser Form in Italien verbindet man auch mit dem Komponisten Tommaso Albinoni (1674-1745), dessen Concerti grossi op. 2 J.S. Bach mit Begeisterung aufnahm. Arnold Schering ${ }^{9}$ führt an, daß man der Form des concerto grosso bei Alessandro Scarlatti (1660 bis 1725) begegnet, obwohl ihre spezifische Verwendung bei diesem Meister der neapolitanischen Oper nicht geläufig war (Scarlatti faßte das concerto grosso im allgemeineren Sinn auf, keineswegs als selbständige Instrumentalform).

Correlis Concerti grossi waren in Italien schon im Jahr 1709 verbreitet, der Komponist hatte sie aber viel früher geschrieben.

6 Bücken, 1. c.

7 Pečman I, $29 \mathrm{f}$.

8 Vgl. Torchi, Wasielewski I, Wasielewski II.

9 Schering, 41. 
Die früheste Datierung bezieht sich auf das Jahr 1682 (?). Ganz sicher schwebten Corellis Concerti grossi dem jungen Händel nach seiner Italienreise als Muster vor; der große Hallenser komponiert seine konzertanten Werke unter Corellis Einfluß (wahrscheinlich war er Corellis Schüler gewesen), was ja bekannt ist.10

Bei der Analyse von Corellis Concerti grossi pflegt man ihre Stilbeziehung zu Cavalli, Torelli, Cesti, Legrenzi, ja sogar za Lully ${ }^{11}$ zu betonen; allgemein wird Corellis meisterhafte, klar geordnete Kompositionsfaktur gerühmt. Schon Arnold Schering ${ }^{12}$ bemerkt, Corellis Concerti grossi seien künstlerisch deshalb so wirksam, weil der Komponist ideale Klangfarben erziele. Außerdem erreiche die konzertante Form in ihnen ihren Gipfel: »Ihren beispiellosen Erfolg verdanken Corellis Konzerte ihrem idealen Ausdrucksgehalt und klassischen Tonsatze; mit ihnen hat die junge Literatur des Concerto grosso bereits ihren Höhepunkt erreicht.«13 Bernhard Paumgartner erkannte, daß sich Corellis Musik in einer elegischen Ausdrucksebene bewegt und dabei ausgesprochen aristokratischen Charakter atmet. ${ }^{14}$ Was Paumgartner hellseherisch, wenn auch nur metaphorisch aussprach, läßt sich zu Ende denken; man darf annehmen, daß der elegische Charakter von Corellis Kantilene einer der Züge jener Tonsprache ist, die den galanten Stil und damit die zur Klassik strebende Entwicklung antizipieren. Allerdings lassen sich bei Corelli noch andere Kompositionsmerkmale entdecken, die man als galant (im wertesten Sinn als vorklassisch) bezeichnen könnte. Sie treten nicht nur in seiner Kantilene zutage, sondern betreffen auch die Tektonik seiner Kompositionen, insbesondere seiner Concerti grossi.

Allgemein gesprochen, besetzt Corelli die Solostimmen der Concerti grossi (also die Stimmen des sogenannten concertino, das auch als principale bezeichnet wird) mit der ersten und zweiten Violine und dem Violoncello. Die Orchesterstimmen (d.i. die tutti) bestehen aus den ersten und zweiten Violinen (violini di ripieno), der Viola, dem Violoncello und Kontrabaß. Die Cembalostimme ist in der Technik des bezifferten Basses geschrieben, der zu Corellis Zeiten meist noch Improvisationscharakter trägt. ${ }^{15}$

Der Aufbau von Corellis Concerti grossi ist einfach. Das Prinzip der horizontalen Stimmführung wird hier noch nicht vom harmonischen Vertikalismus überwunden. Die Konzerte wachsen aus monothematischen Fundamenten, wie dies zur Zeit des Hochbarocks der Fall war. Offenbar knüpft das Kontrapunktische dieser Concerti

${ }^{10}$ Hawkins, Burney, Falyolle, Vatielli, Pincherle. Vgl. auch Paumgartner, MGG II, 1952, Spalte 1668-1679.

11 Paumgartner, 1.c.

12. Schering, 41.

13 Schering, daselbst.

14 »Aber kein ital. Meister jener Zeit hat die aristokratische Würde des Corellischen Stils, das Pathos, die elegische Ausdruckshaltung seiner Kantilene.« (Paumgartner, 1.c.)

${ }_{15}$ Die Aufführung der Concerti grossi ohne Cembalo scheint uns fragwürdig zu sein. 
grossi an ältere Muster an und wächst aus der italienischen Tradition des Instrumentalschaffens vor Corelli. ${ }^{16}$ Die zwölf Concerti grossi aus Corellis gleichnamiger Reihe op. 6 vertreten einersets den Typ der instrumentalen Kirchenkomposition, anderseits das Schema der weltlichen Formen des instrumentalen Schaffens. Wie aus dem Text auf dem Titelblatt der Sammlung Concerti grossi con duoi Violini, e Violoncello di Concertino obligati, e duoi altri Violini, Viola e Bassi di Concerto Grosso ad arbitrio, che si potranno radoppiare (...). Opera Sesta. Parte Prima.$^{17}$ hervorgeht, gehören die ersten acht Konzerte zum Typ »da chiesa" (Kirchentyp). Die Konzerte Nr.9 bis 12 kann man dem Typ »da camera (Kammertyp) zuordnen, was ja auch ihre Bezeichnung verrät: Preludia, Allemande, Corrente, Gighe, Sarabande, Gavotte e Minuetti (...). Parte Seconda per Camera. ${ }^{18}$

Der Komponist erweist sich in allen Konzerten des sechsten Opus als Meister des ruhigen, edlen Ausdrucks, der die Einflüsse der italienischen Volksmelodik nicht verleugnet. Er verwirft die rein technische Entwicklung des musikalischen Gedankens und schreibt reich durchkomponierte Sätze, die auf dem Prinzip einer sublimierten kontrapunktischen Technik beruhen und vor allem durch ihre Ausdruckskontraste wirken.

Corellis Concerti grossi sind vom melodischen Standpunkt vielleicht am interessantesten. Namentlich in den konzertanten Kompositionen des Typs »da camera" nimmt er das "Raketenhafte« der späteren vorklassischen Tonsprache, vor allem eines Stamic und Richter vorweg. Die Gavotte aus dem IX. Konzert (Notenbeispiel 1) ${ }^{19}$

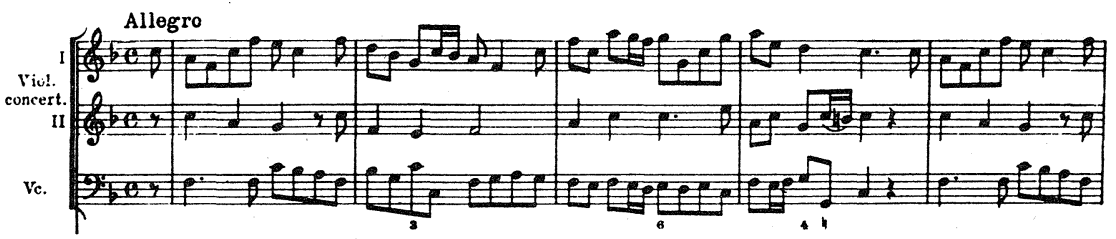

stellt in dieser Hinsicht einen hochinteressanten Beleg vor. Zerlegte "Raketen" - Akorde, die in der melodischen Linie der ersten konzertanten Violine erscheinen, sind später nicht nur bei Antonio Vivaldi, sondern vor allem bei den Symphonikern des Mannheimer Kreises üblich. Diesen melodischen Typ finden wir übrigens schon im Allegro des VII. Konzerts (Notenbeispiel 2) ${ }^{20}$ und an einer Reihe anderer Stellen.

16 Schering, 1. c.

17 Corellis Concerti grossi Op.6, Leipzig 1937, Taschenpartitur, Edition Peters (Verlagsnr. 11362).

18 Daselbst.

19 Corelli, Taschenpartitur, S. 155.

20 Daselbst, S. 112, Allegro 3/4, Takt $10-17$ in der oberen Stimme. 


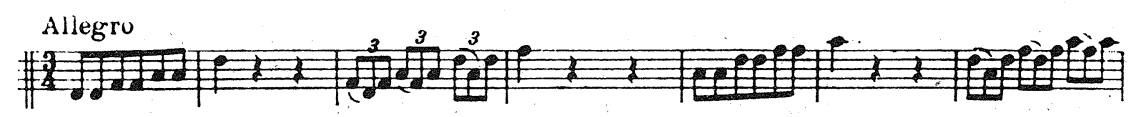

In den langsamen Sätzen von Corellis Concerti grossi entwickelt sich eine Melodik, die vom Stamme der volkstümlichen Pastorellen ist, wie sie in der italienischen Musik des 18. Jahrhunderts, aber auch im tschechischen melodischen Bereich dieser Zeit erscheinen. Corelli ist es gelungen, die Form der im Tempo gemäßigten Gigue mit einer tiefen und rührenden Melodik $\mathrm{zu}$ erfüllen, die sich im Ausdruck dem melodischen Habitus der späteren Pastorale G. F. Händels (Notenbeispiel 3) 21 $^{1}$ nähert. Diese Pastoralmelodik gehört nun

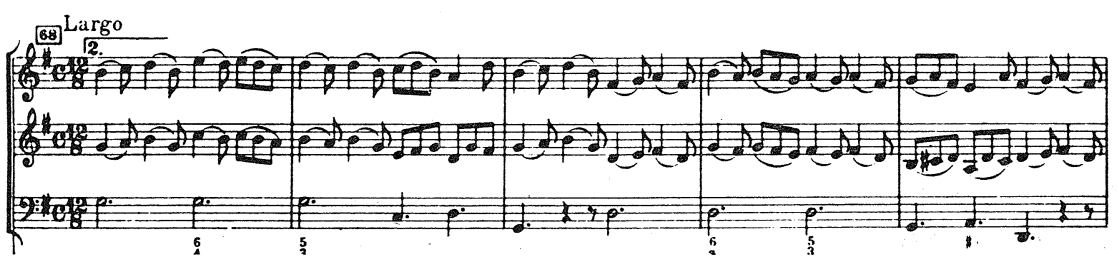

eigentlich vom Stil aus gesehen schon nicht mehr dem historischen Bereich des Hochbarocks an, weit eher läßt sie sich den wirkungsvollen, aber bereits ausgesprochen vorklassischen melodischen Kreationen des galanten Zeitalters zuordnen.

Corelli arbeitet mit der barocken monothematischen Technik. Das bedeutet aber keineswegs, daß nicht wenigstens Andeutungen des

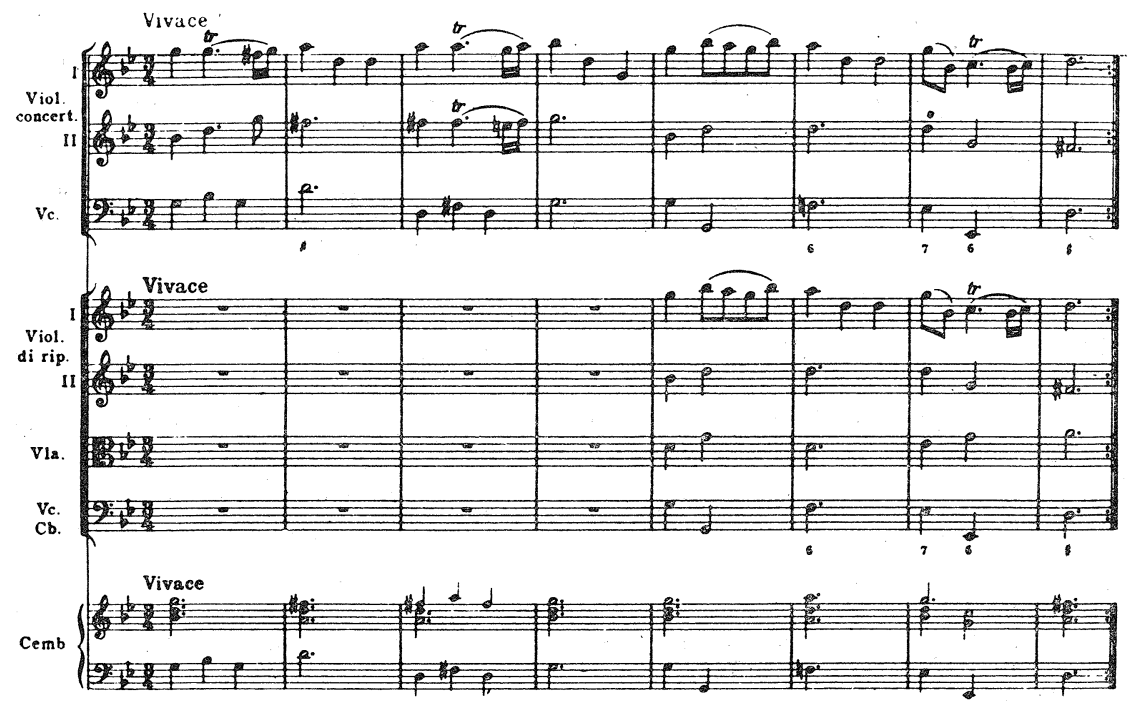

${ }^{21}$ Daselbst, 141: Pastorale ad libitum. 

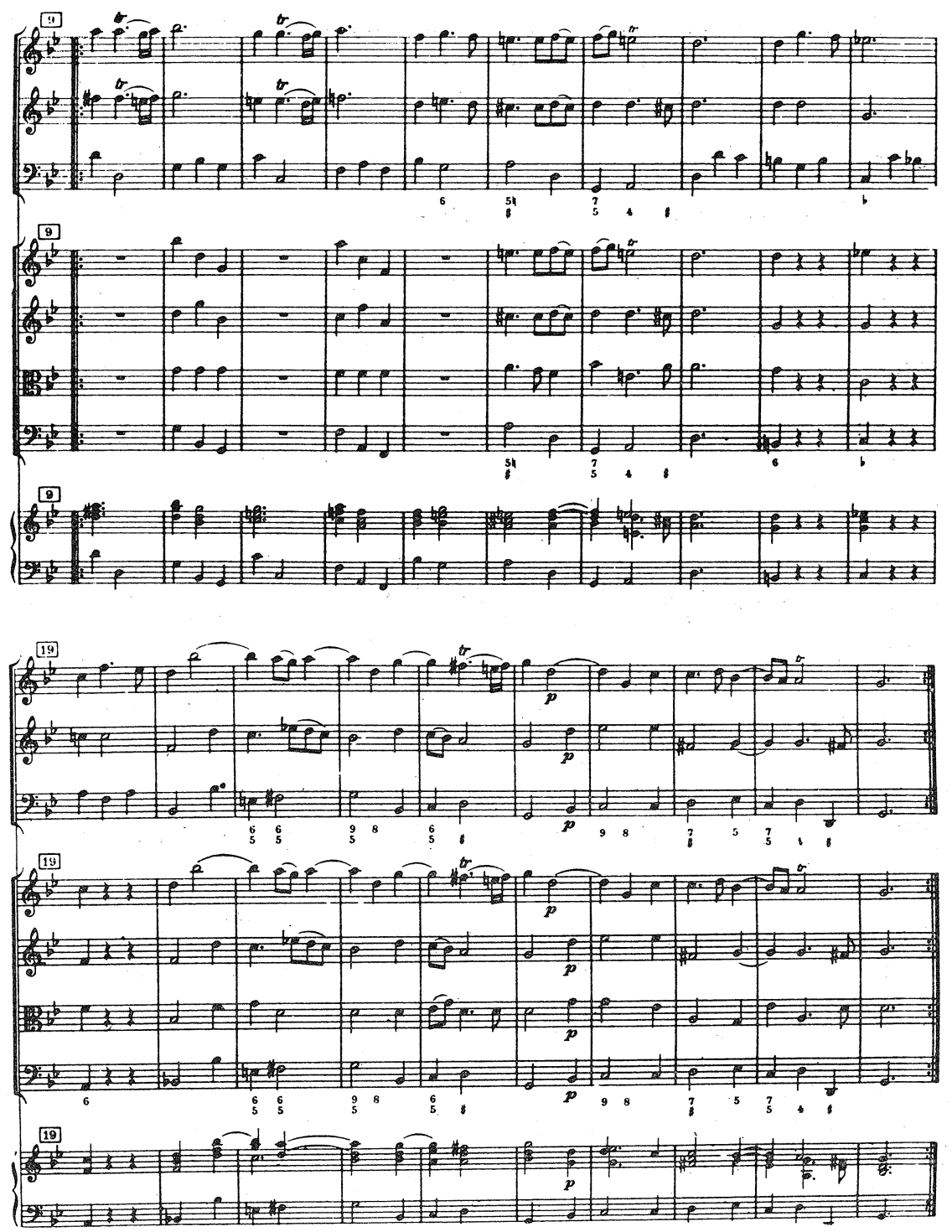

thematischen Daulismus, abermals als ausgesprochen vorklassisches Zeichen, erscheinen. In seinen Sonaten, aber auch in den Concerti grossi (beispielsweise im Vivace des VIII. Konzertes, Notenbeispiel $4)^{22}$ entwickelt sich in den zweiten Teilen der Sätze »da a camera" ein relativ reicher harmonischer Plan, der zwar noch vorwiegend (man könnte fast sagen ausschließlich) auf der Sequenzentechnik

${ }_{22}^{2}$ Daselbst, 136-137. 
beruht, aber bereits eine Art monothematischer barocker Durchführung erkennen läßt. ${ }^{23}$ Die zweiten Teile von Corellis zweiteiligen Sätzen bieten auch sonst noch interessantes Studienmaterial zur Entwicklung der barocken Sonatenform. Ein Vergleich vor allem mit Domenico Scarlattis Werk (siehe weiter unten) müßte zeigen, daß die historisch bedeutend jüngere klassische Sonatenform mit einer ihrer Wurzeln im Werk Corellis fußt, das in dieser Hinsicht wieder beispielweise die in Domenico Scarlattis Cembalo-Essercizi erscheinende Technik vorweggenommen hat. Und von Scarlatti führt nur ein Schritt zu den ausgesprochen vorklassischen Strukturen, die sich in den dreißiger und vierziger Jahren des 18. Jahrhunderts nicht nur im italienischen Entwicklungskontext sondern auch im übrigen Europa $\mathrm{zu}$ formen beginnen.

Auch die klare melodische Periodizität des musikalischen Gedankens, befreit von dem schwerblütigen barocken Ausdruck, trägt bei Corelli zur lichten, ausgeglichenen Gliederung des Musiksatzes bei (Notenbeispiel $5^{24}$ und $6^{25}$ ). Corelli, der schon eigentlich vorklas-
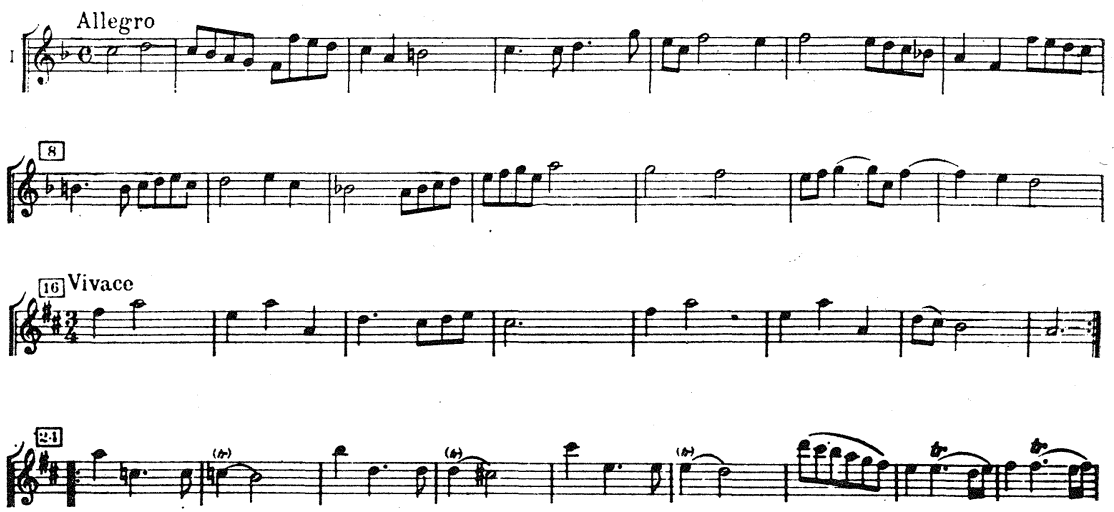

sisch denkt, arbeitet zwar noch mit der horizontalen kontrapunktischen Technik; seine Harmonie ist aber nicht mehr das bloße Ergebnis der horizontalen Stimmführung, sie besitzt eine vielseitigere Funktion, die aus einer breiteren, spezifischeren Auffassung des Harmonischen hervorgeht; während noch Monteverdi zwischen Dur, Moll und alten Kirchenmodi oszilliert, ist Corellis harmonisches Denken schon eindeutiger und nähert sich dem harmonischen Denken der Klassik. Wesentlich ist, daß Corelli harmonisch bestimmte Gebilde, meist im Dur-Charakter, komponiert, die sich durch eine galante Graziosität auszeichnen. ${ }^{26}$

${ }^{23}$ Die »monothematische Barockdurchführung" ist mit der klassischen Durchführung nicht identisch.

${ }_{24}$ Corelli, Taschenpartitur, 32. I. Violine.

25 Daselbst, 63.

26 Vgl. Taschenpartitur, 205 (Notenbeispiel 7, Sarabande) oder daselbst, 101 (Notenbeispiel 8, Vivace). 

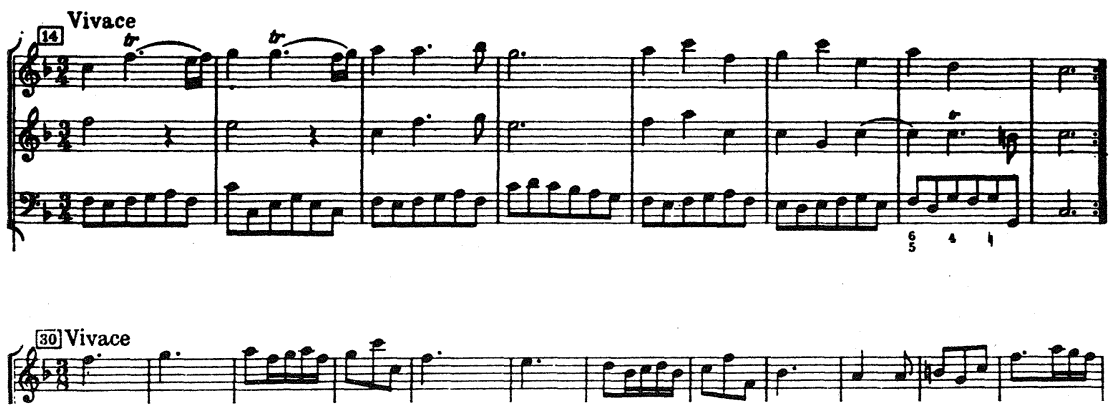

Corellis Beziehungen zum vorklassischen musikalischen Denken könnten wir selbstverständlich noch eingehender dokumentieren. Doch sollte schon aus unseren kurzen Ausführungen hervorgehen, daß sein Schaffen zu jenen Phänomenen der italienischen Musik des 18. Jahrhunderts gehört, die zur Zeit des Hochbarocks dem neuen musikalischen Denken kräftig Bahn brachen (vor allem in der Auffassung der Melodik und Harmonie), ohne daß es noch $\mathrm{zu}$ einer Störung der barocken Kompositionsarchitektonik gekommen wäre. Corellis Concerti grossi bringen interessante Belege dafür, daß es möglich war, auch den Rahmen der nüchternen, strengen Kompositionsformen des Barocks mit einer innerlich geklärten Tonsprache zu erfüllen, die die Ausdrucksobjektivität der kommenden Klassik signalisiert. Natürlich wird es angezeigt sein, die Frage der Vorbereitung der Klassik in der spätbarocken Musik Italiens in Zukunft noch gründlich $\mathrm{zu}$ untersuchen.

Bisher haben wir uns auf eine vergleichende Charakteristik jener Werke eingestellt, bei denen es zu Bedeutungsverschiebungen innerhalb der Kompositionsstrukturen kommt. Dies gilt auch für andere Meister, mit denen wir uns nun befassen wollen.

Wir haben schon an anderer Stelle geschrieben, ${ }^{27}$ daß auch die Ausdruckmittel der sogenannten neapolitanischen opera seria - zumindest mittelbar - die neue Epoche des Rokokos in der Musik vorbereitet haben. Metastasios Prinzipien eines lyrisch verfeinerten Librettos, die in mancher Hinsicht sogar als Vorboten von Gluck-Calsabigis Reformen anzusehen sind, ${ }^{28}$ beeinflußten den Stil dieser Oper (ihr bedeutendster Repräsentant war Alessandro Scarlatti, gest. 1725), in der eigentlich schon seit Anfang des Jahrhunderts Voraussetzungen des kommenden "galanten" Stils keimen: Die Periodizität des musikalischen Gedankens, die folgerichtige Dreiteiligkeit der Arie $(\mathrm{A}-\mathrm{B}-\mathrm{A})$, aber auch die Beliebtheit von Scarlattis Tempoplan der Ouvertüre rasch - langsam - rasch. Das ist übrigens ebenso bekannt wie die Tatsache, daß dieser Ouvertürentyp später einer der Taufzeugen bei der Geburt der vorklassischen Symphonie eines Monn und Wagenseil und der Mannheimer gewesen ist. Aller-

27 Pečman II, Pečman IV.

28 Rolland, $147 \mathrm{f}$. 
dings wurde noch nicht gebührend betont, daß es die neapolitanische ernste Oper war, die eine »ätherische«, zum Lyrischen neigende Art der Instrumentation kodifizierte; dies entsprach den praktischen Erfordernissen der musikdramatischen Aktion und wurde nicht nur von den begrenzten Betriebsmitteln des neapolitanischen Opernorchesters, sondern auch vom Streben nach Verständlichkeit des gesungenen Wortes diktiert. Die einzelnen Instrumente des neapolitanischen Opernorchesters werden allmählich selbständig, jedes von ihnen $^{29}$ wird zum Träger eines spezifischen Ausdrucks: aus Instrumenten der Füllstimmen werden "melodische " Instrumente. ${ }^{30}$ Das Orchester zeichnet auch mit bescheidenen Mitteln treffend das Psychologische der Bühnenhandlung und es gibt bereits ziemlich genau ausgearbeitete Regeln, wie man mit Hilfe bestimmter Instrumente nach innen und außen gerichtete Situationen $\mathrm{zu}$ charakterisieren hat. ${ }^{31}$ All dies ist für die neapolitanische Oper, die erste lyrische ernste Oper der Welt, typisch. Die Starre und Einlinigkeit des musikalischen Denkens schmilzt, zum Träger des Ausdrucks wird die Melodik, von Instrumenten präsentiert, die Schritt für Schritt zu immer größerer Freiheit gelangen und manchmal auch solistisch exponiert werden. Obwohl also die Meister der Neapolitanischen Schule die Funktion mancher Ausdrucksmittel neu gedeutet haben, darf man nicht übersehen, daß andere Komponenten des Ausdrucks - die rein virtuose Auffassung des Gesangs oder die Einhaltung stereotyper Librettomotive - die Entwicklung zu hemmen begannen und von der jüngeren Generation mit Recht abgelehnt wurden.

Schon in der bekannten satirischen Schrift Benedetto Marcel$\operatorname{los}^{32}$ wird den negativen Seiten der alten Oper ein Zerrspiegel vorgehalten. Aber auch voreingenommene Beobachter vom Typ eines Voltaire, Mattheson, Rousseau, die u.a. gegen die retardierende Länge der italienischen Seccorezitative protestieren, können nicht umhin, die Ausdruckskraft anzuerkennen, die manche Opernstellen mit starken und tiefen menschlichen Affekten ausstrahlen. ${ }^{33}$ Bei den großen Vertretern der neapolitanischen Oper A.Scarlatti, L. Vinci, L. Leo, G. B. Pergolesi finden wir leidenschaftliche Seccorezitative, in denen bereits der Gedanke der "zusammenhängenden Melodie« (melodia continuata) schlummert, der seinen italienischen Erfüller vor allem in Jommelli gefunden hat. Hier entsteht ein eigenartiger Ausdrucksbereich, der zweifellos eine Vorstufe des Rokokos ist. Schon bei L. Vinci gewinnt das Rezitativ ariosen Charakter und die Grenzen zwischen Rezitativ und Arie beginnen zu verschwimmen. ${ }^{34}$ Ähnlich

\footnotetext{
man, II.

30 Vgl. z. B. die Instrumentierung der Bratsche oder des Fagotts.

31 Vgl. Pečman II, Pečman IV.

32 Marcello.

33 Bücken, $33 \mathrm{f}$.

34 Vgl. das recitativo "Perché tua figlia io sono" aus Vincis Oper Catone in Utica (Akt I, Szene 1).
}

${ }^{29}$ Über die Besetzung des neapolitanischen Opernorchesters vgl. Peč- 
die ernsten Opern Pergolesis ${ }^{35}$ - sie tragen auch in der Melodik galante Züge. Selbst Alessandro Scarlatti verharrt nicht mehr im Kreis des älteren Denkens und stellt das homophone Prinzip in den Vordergrund, das einige Jahre später in der Musik des Rokokos und der Klassik dominieren sollte. Als wirksamer und überzeugender Beleg für dieses neue musikalische Denken sei ein Abschnitt aus Scarlattis Kantate "Quanto piace» angeführt, dessen Melodik die volkstümliche italienische Provenienz ebenfalls nicht verleugnet (Notenbeispiel 9);36 die Oberstimme verrät noch die Herkunft aus kon-
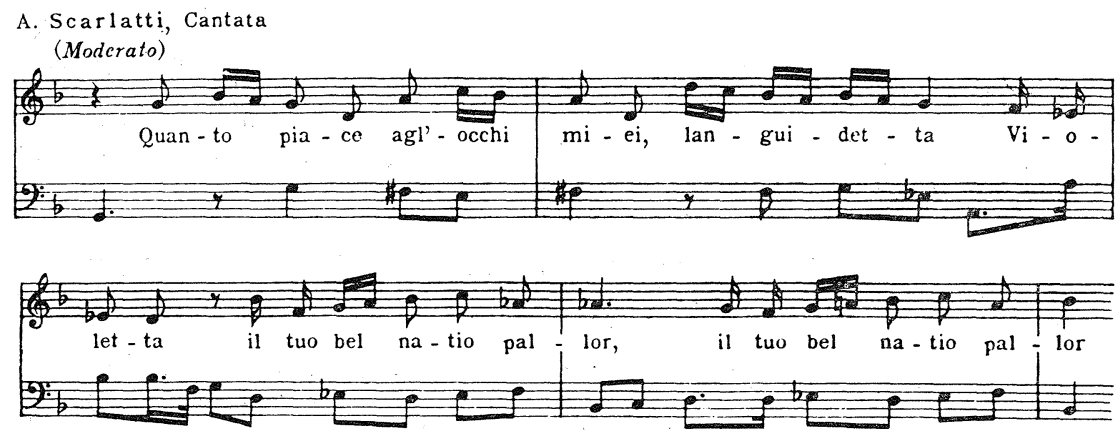

trapunktischen Prinzipien, wird aber bereits homophon behandelt. Dasselbe gilt für das folgende Beispiel aus der Kantate »Tu parti« desselben Autors (Notenbeispiel 10), ${ }^{37}$ die ausgesprochen homophon

A. Scarlatti, Cantate: Tu parti
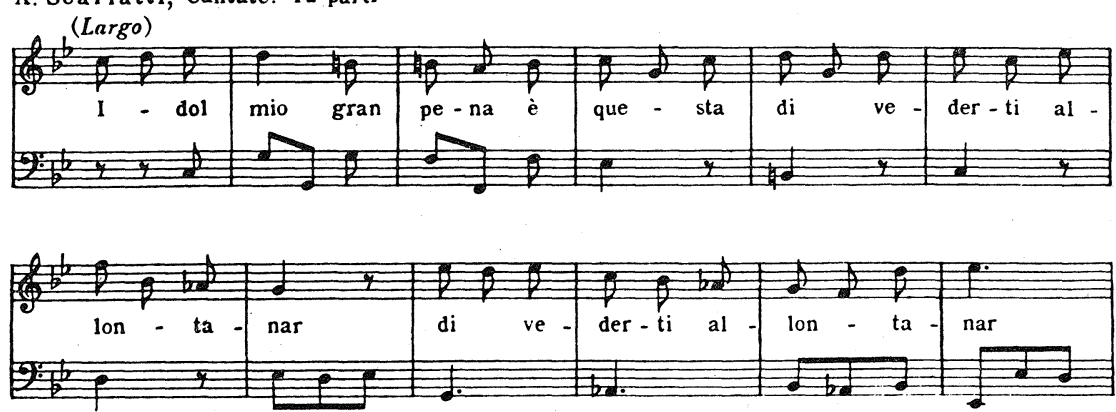

ist und auch die elegische Note der späteren, typisch rokokohaften neapolitanischen Kreationen deutlich ahnen läßt. Beachten wir, daß Scarlatti, aber auch Vinci, Leo und Pergolesi, Arien im dreiteiligen Schema schreiben, deren Kompositonsprinzip sich aber der barocken allmählichen (monothematischen) Entwicklung des musikalischen

35 Z. B. in der Oper Olimpiade.

36 »Quanto piace agl'occhi miei, languidetta Violetta il tuo bel natio pallor«, vgl. Bücken, 34 .

3. "Idol mio gran pena è questa di vederti allontanar", vgl. Bücken, 35. 
Gedankens entzieht; eher geht es hier um eine symmetrisch konstruierte, also typisch galante Melodik, die kleine Zwei- und Viertaktgebilde aneinanderreiht und nicht selten auch die Dreitaktsymmetrie ausnützt. Diese Verfahren korrespondieren mit der häufigen Wiederholung kurzer melodischer Fragmente, die zur melodischen Miniatur zielen, wir zögern sogar nicht zu behaupten: zur Manier der späteren "Schusterflecken", wie sie besonders in den Durchführungen kleinerer Komponistenpersönlichkeiten der Klassik auftauchen. So kurzatmige, durchaus unbarocke Melodie reiht Pergolesi beispielsweise in seiner Oper »Olimpiade« (Notenbeispiel 11). ${ }^{38}$ Es
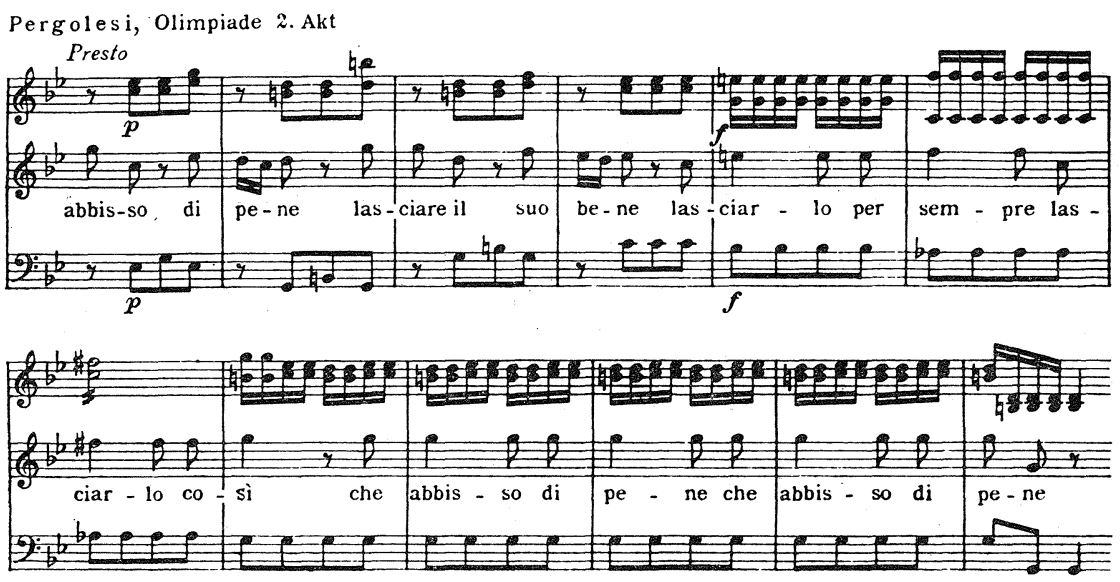

ist als hörten wir einen Vorhall der echten Buffomelodik. In der ernsten Oper mußte dieser melodische Typ sicher befremdend wirken. Sein rechter Ort ist nämlich in der italienischen opera buffa, deren meisterhafter Vertreter Pergolesi war. Man darf also mit Ernst Bücken ${ }^{39}$ übereinstimmen, die ersten "galanten" neapolitanischen Komponisten hätten auf dem Gebiet der opera seria die schönsten Früchte vor allem in ihren rührend elegischen Arien gepflückt, die $\mathrm{zu}$ echten Vorzeichen des sentimentalen, empfindsamen Musikstils wurden.

Es ist wohl unnötig, in diesem Zusammenhang den Gedanken zu entwickeln, daß die opera buffa seinerzeit die Hauptträgerin von Rokokostimmungen und -verfahren gewesen ist, weil sie ja allgemein als eine Art Retterin der Oper gilt. Wie immer wir auch ihre Funktion und progressive Bedeutung beurteilen, gewiß ist, daß sie den starren Opernformen neues Blut einflößte. Sie ging der dramatischen Bühnenwirksamkeit komisch grotesker Situationen nach und gelangte zu knapp geformten Dialogen. Aus dem Urtyp der soge-

38 Olimpiade, II. Akt. Bücken, daselbst.

39 "Ihr Bestes aber gab die Opernmusik der ersten galanten neapolitanischen Komponisten in ihren rührenden, elegischen Arien, echten Vorboten des empfindsamen Zeitalters.« (Bücken, 36.) 
nannten commedia musicale napoletana, aus der komödialen Bühnenform »La Cilla« (1707), entstanden einige Buffo-Opern, die allerdings durch das Sieb der Zeiten gefallen sind, obwohl sie von Meistern wie Vinci, Scarlatti u.a. stammen. Die Librettoautoren dieser Buffos $^{40}$ waren Francesco Antonio Tullio, Bernardo Saddumene und G.A. Frederico; sie verwenden bedenkenlos volkstümliche, oft recht derbe Elemente, stützen sich auf dem Leben abgelauschte Situationen und lieben extreme Charakterkomik. Doch erst mit Federicos und Pergolesis "La serva padrona" (1733) wurde ein repräsentatives, auch heute noch lebensfähiges Werk geboren. ${ }^{41}$ In dieser Musik findet man bereits das Prinzip der klassischen Melodiegliederung, die Melodik, die mit häufigen Wiederholungen kurzer Perioden und Abschnitte arbeitet, ist meist diatonisch, klar und übersichtlich. Hier kam das typische buffose Brio zur Welt, das dann zu einem der Merkmale der klassischen Tonsprache werden sollte. Mit den Grundsätzen und Gefühlen des kommenden galanten Zeitalters steht vor allem die Lebensnähe, das "Realistische" des Sujets und die Art seiner Äußerung im Einklang. Der Streit zwischen opera seria und opera buffa war zu Gunsten der neuen Buffo-Oper entschieden. Als wäre Metastasios Gedanke in Erfüllung gegangen, daß der Grundzug des Musikdramas im Streit zweier Hauptprinzipien der menschlichen Seele, der Leidenschaft und des Verstandes beruht. ${ }^{42}$ Während die opera seria vom Sujet an über die Bühnengestalten bis zur historischen Wahrheit einfach alles idealisiert, während sie also die Bühne zum leidenschaftlichen Kampfplatz von streng schematisierten Ideen macht, deren Sprachrohr die handelnden Personen sind, führt die opera buffa das realistisch-rationale Prinzip in die Entwicklung ein, weil sie die unbeschönigte dramatische Wahrheit in der künstlerischen Transformation realer, meist possenhafter Lebensbilder darstellen will. Das Volkliche nimmt überhand, oft in grobkörniger und keineswegs wählerischer Art, wird aber ganz anders aufgefaßt als in der ernsten Oper, die keine volkstümlichen Figuren im echten Sinne kannte; 43 das "Volk« vertraten stumme Statisten oder der dramatisch kaum tragfähige (und auch selten exponierte) Chor, der meist schwach besetzt war und als statischer Kommentator der Handlung am Ende der Oper oder ihrer Akte, in großen Auftritten der Herrscher, in Aufzügen, Kampfszenen u. a. auftrat. Die opera buffa brachte Menschen aus Fleisch und Blut, Gestalten volkhafter Prägung. Kühn geißelt sie menschliche Untugenden und kritisiert die verfallende Aristokratie. Die opera buffa ist vom Parnaß herabgetreten und stellt sich in die Dienste des erstarkenden Bürgertums.

${ }^{40}$ Siehe z. B. folgende Opern: Zite n'galera (1722) von Leonardo Vinci (Text: Bernardo Saddumene); Paglietta geluso (1726, Text: Bernardo Saddumene). Einige Buffo-Opern komponierte auch A. Scarlatti. Siehe unten.

${ }^{41}$ Früher als Pergolesis La serva padrona wurde das Intermezzo Pimpinome (1725) von G. Ph. Telemann komponiert.

42 Metastasios Brief vom 10.6.1747.

43 Vgl.z. B. die Figur eines Gärtners in Händels Oper Xerxes. Diese Figur ist noch im stile semiseria geschrieben. 
Niemals hat sie die Bande zerrissen, die sie mit dem Volklichen verknüpften. Während in der opera seria die Personen ihre »affetti« in stereotyper Weise äußern, negiert die opera buffa alles Konventionelle und zielt auf das echte Leben, dessen Wahrheit und Gesetze sie bereits objektivisiert. Zum ersten Mal in der Geschichte der Oper konnte also der Besucher das im Geschehen verborgene Objektive auf sich beziehen, was in der opera seria nicht möglich war: dort ging es zwar ebenfalls um den Ausdruck von allgemein verbindlichen Ideen. Sie bewegten sich jedoch auf der allzu abstrakten Ebene des ideellen Widerstreites, statt aus menschlichen Geschicken und Erfahrungen hervorzugehen. Deshalb tritt auch die »bellezza« der Buffo-Oper in den Hintergrund, um der »verità " zu weichen. Die Wahrheit siegt über die Schönheit. ${ }^{44}$

Bekanntlich wurde Alessandro Scarlatti zu einem der ersten Bahnbrecher der opera buffa. Wir haben schon gesagt, daß sich seine Melodik bereits in der ernsten Oper in kleinere Abschnitte bröckelte, was den Komponisten gewissermaßen dazu prädestinierte, seine Kunst dem neuen Typ der dialogischen opera buffa zu widmen. Er erwies sich als Meister der realistischen dramatischen Schilderung und verstand es die Charaktere der handelnden Personen scharf $\mathrm{zu}$ unterscheiden, deren Dialoge von einem Strom frischer Musik getragen werden. Das ist z. B. im dritten Akt der Oper „Cambise der Fall, in der scherzhaften Szene Frau Lydias und ihres Verehrers Sergio (Notenbeispiel 12), wo die musikexpressive Kompo-

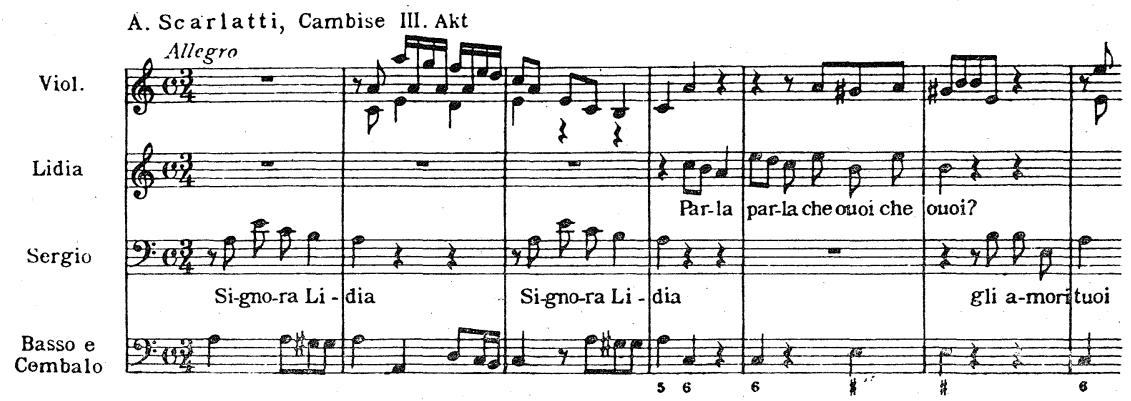

nente zwar reich, aber nicht hypertrophisch ist und der Bühnenhandlung voll gerecht wird. Ernst Bücken betont, ${ }^{45}$ Scarlattis Melodik lehne sich durchaus an volkliche Muster an, was man nicht nur an der reichen Verwendung der siciliana, sondern auch am beschwingten Verlauf der Seccorezitative erkennt, die ihre Zugehörigkeit zur volkstümlichen commedia musicale vor allem in der naturalistischen Nachahmung des Tonfalls der menschlichen Rede beweisen. In der echten Buffo-Oper, wir denken hier an Pergolesis "La serva padrona", kommt diesem sprachlichen Tonfall bei der Charakterisierung der handelnden Personen hohe Bedeutung zu.

${ }_{44}$ Deshalb lobt z. B. Rousseau die Gattung der opera buffa.

45 Bücken, 39. 
$\mathrm{Zu}$ Pergolesi sei noch wenigstens gesagt, daß in seiner soeben erwähnten kurzen opera buffa ein neues wichtiges Bauelement erscheint: die ganze Oper wird von einem kurzen Kleinmotiv durchwirkt, das aus einer Achtelpause und drei Achtelnoten besteht und eines, aber nicht das Einzige vereinheitliche Element der Musik darstellt. Beachten wir beispielsweise dieses fallende Motiv in Ubertos Gesang aus dem ersten Akt, wo es sich in der Arie "Sempre in contrasti« (Notenbeispiel 13) bei der Frage „Che dici tu? Non è cosi?

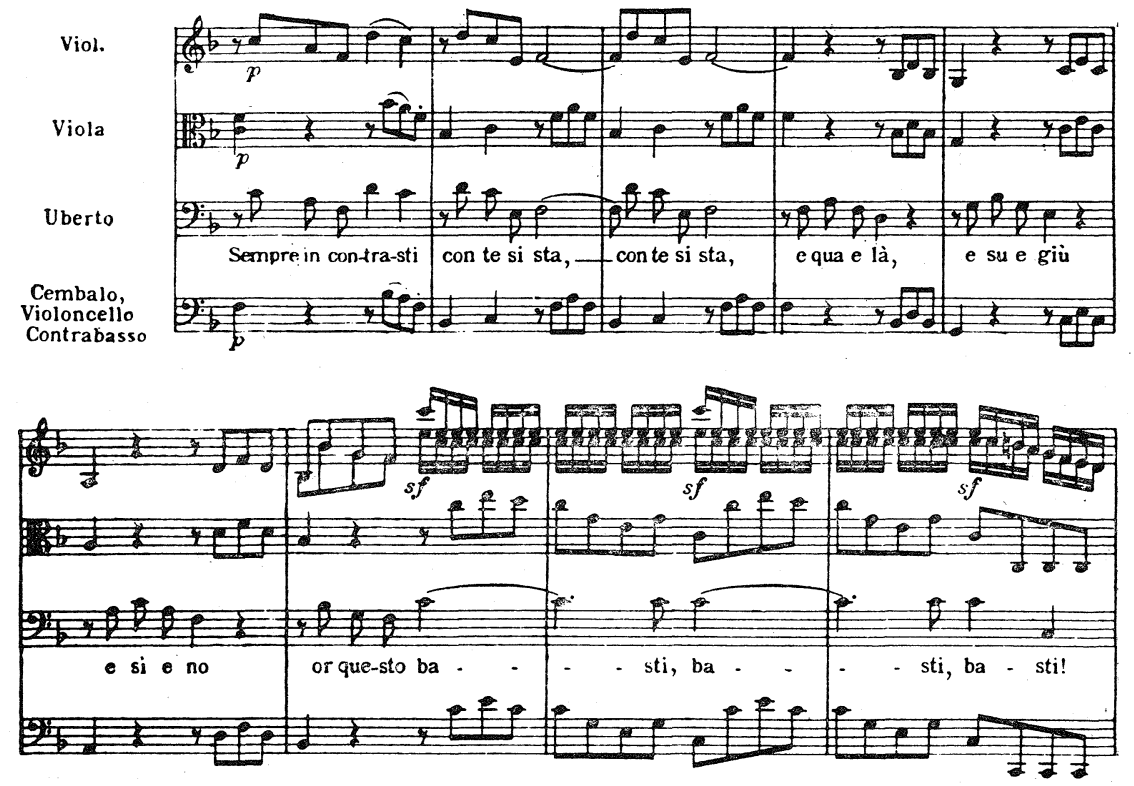

Ah?« (Notenbeispiel 14) zu einem steigenden Motiv wandelt.

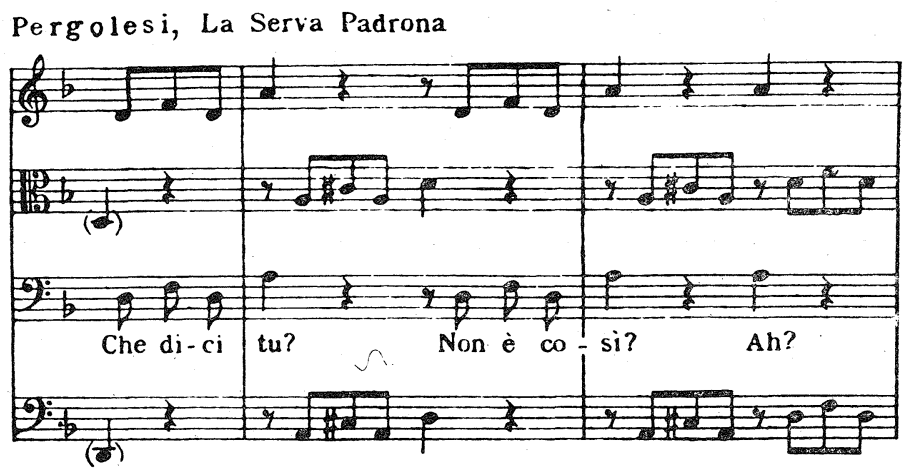

Es könnte scheinen, als gehe es hier um die übliche Motivarbeit. Wenn man aber bedenkt, daß dieses svereinheitlichende" Motiv in der Technik einer Art »Durchführung« behandelt wird, die auf einem 
relativ reichen harmonischen Plan und dem Imitationsprinzip beruht, kommen bereits neue kompositionstechnische Zusammenhänge ans Licht, die diese Musik in die Entwicklung zur vorklassischen Symphonie stellen, eine Entwicklung, die von der Sonatendurchführung der ersten Sätze gekrönt wurde. Es ist nicht uninteressant, daß Pergolesis »Durchführung" ebenfalls auf dem Prinzip der Teilung, ich zögere nicht zu behaupten: auf dem Prinzip der Zergliederung größerer melodischer Gebilde beruht. Also abermals ein Vorbote der Kompositionsgrundsätze der kommenden Klassik! Natürlich müßte man in analytischer Detailarbeit vergleichend beweisen, ob und wie dieses Prinzip Pergolesis mit der Kompositionsweise der späteren Meister der Klassik unmittelbar zusammenhängt.

Verfolgen wir nun möglichst knapp, in welchem Maß die italienische Instrumental- und Kammermusik den "galanten" Ausdruck der Rokokoperiode eingeleitet hat. Die Frage ist äußerst schwer zu beantworten, weil sie bisher noch nicht umfassend behandelt wurde, ja es fehlen sogar ins Gewicht fallende Einzelstudien. Bei dem vorhin besprochenen Beitrag von Corellis Concerti grossi gedachten wir die Priorität der italienischen Musik bei der Entstehung der Stilmerkmale der Vorklassik im allgemeinen zu belegen. Wir wählten diese Werke deshalb, weil es sich um für Corelli typische Kompositionen handelt, die $\mathrm{zu}$ den mustergültigen Arbeiten des Hochbarocks zählen, und waren bemüht $\mathrm{zu}$ beweisen, daß die ersten Anzeichen eines vorklassischen musikalischen Denkens eigentlich bereits um das Jahr 1700 erscheinen. Das ist unserer Meinung nach die früheste Zeit des Auftauchens prägalanter Elemente in der italienischen Musik. Aus chronologischen Gründen mußten wir dann Fragen der opera seria und opera buffa streifen. Um das Entwicklungsbild abzurunden, haben wir nun zu einigen Komponisten der ersten Hälfte des 18. Jahrhunderts zurückzukehren, die als hervorragende Vertreter der Instrumentalkomposition eine wichtige Rolle im Rahmen unseres Themas spielen.

Wie bereits angedeutet, ist es auf dem Feld der italienischen Instrumentalmusik sehr bald zu Eingriffen in die barocken Kompositionstechniken gekommen. Das Problem der Überwindung des Barockstils läßt sich in einige Grundfragen gliedern: Fragen

1) Die Entstehung der vorklassischen Sonatenform, mit der die

2) der Entwicklung des zweiten Themas in der Struktur der Sonatenform und

3) der Entstehung der Durchführung eng zusammenhängen.

Neben diesen strukturellen Erscheinungen geht es hier noch

a) um das Zurücktreten der Polyphonie (des Kontrapunktes) zu Gunsten der harmonischen Komponente, und damit zusammenhängend

b) um die Entstehung eines neuen Typs der regelmäßig gegliederten Melodie, an deren Knotenpunkten eben die Harmonie eine wesentliche Rolle spielte. 
Die übrigen Fragen, die ebenfalls nicht unwichtig sind, wollen wir hier beiseitelassen. ${ }^{46}$ Sie wurden an anderer Stelle umrissen (vergl. Anm. 46).

Die italienischen Komponisten des Hochbarocks haben die Voraussetzungen für die Entstehung der Sonatenform des klassischen Typs geschaffen. Zuerst schreiben sie Sonaten des Barocktyps, bei denen man jedoch Andeutungen des zweiten Themas entdeckt. Es kommt $\mathrm{zu}$ einem interessanten Prozeß, in dessen Verlauf dem formalen Grundriß der alten Barocksonate Verfahren einverleibt werden, deren Zeit eigentlich noch nicht reif war. Obwohl der Themendualismus noch nicht existiert, spielt sich in den zweiten Teilen der zweiteiligen Sonatensätze etwas Neues ab: der Versuch mit dem im ersten Teil exponierten Thema zu arbeiten. Anfangs handelt es sich nur um geringfügige Wandlungen, die sich auf Änderungen der Tonart beschränken (die Grundtonart wird zu Beginn des zweiten Teils durch die Tonika auf der Dominante ersetzt). Etwas später greift man auch in die Struktur des Themas ein, aus Gründen des Kontrastes wird das Thema selbst zu Beginn des zweiten Teils modifiziert. Aber diese Modifikationen sind bloß ein tastender Anfang: das zweite Thema war noch nicht ersonnen, weil die harmonischen Voraussetzungen fehlten. Zuerst war es notwendig, die Alleinherrschaft der Polyphonie zu brechen und die Homophonie mit einer neuen Auffassung der Harmonie als Element $\mathrm{zu}$ installieren, das funktionell (d.h. schon an und für sich) imstande ist, den Kompositionssatz entscheidend mitzuformen.

Neben Corellis Werken sind für diese Entwicklung noch die Kompositionen seines jüngeren Zeitgenossen Ferrucio dall'Abaco (1675-1742) charakteristisch. Abacos Triosonaten bringen zum ersten Mal Elemente, die die Einheit der barocken Form schüchtern antasten, und einen neuen Aspekt auf die Architektur des Satzes andeuten. Die melodische Linie des zweiten Themas (sofern von einem solchen überhaupt die Rede sein kann) ist noch mit jener des ersten verknüpft. Wenigstens an einem Beispiel wollen wir dies näher erläutern. Während das erste Thema von Abacos Triosonate op. $3 \mathrm{Nr} .6$, ihr einleitender Allegrosatz, auf einer rhytmisch geraden Achtelbewegung aufgebaut ist (Notenbeispiel 15) ${ }^{47}$ und von kontra-

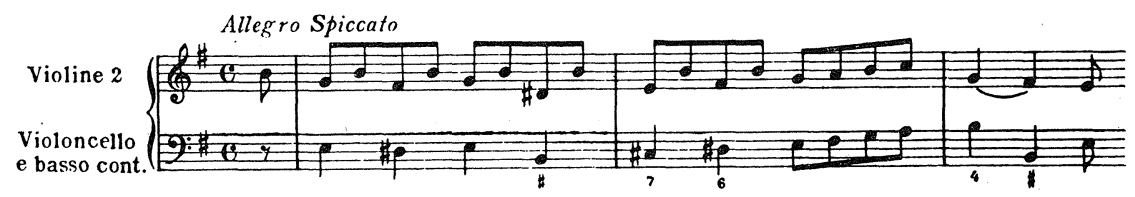

punktischen Kompositionsgrundsätzen ausgeht, ist das zweite Thema

${ }^{46}$ Es handelt sich um die neue Auffassung der Dynamik, um die Entwicklung des Instrumentariums, ferner um die Kodifizierung einer neuen Instrumentalbesetzung, um ein neues Klangideal der galanten $\mathrm{Mu}$ sik usw.

47 Bücken, 15. 
(Notenbeispiel 16) ${ }^{48}$ schon luftiger, freier, in Imitationstechnik ausgearbeitet, die auf der Augmentation des ersten Themas beruht, und mit meist auf den leichten Taktzeiten vorgeschriebenen Trillern ver-
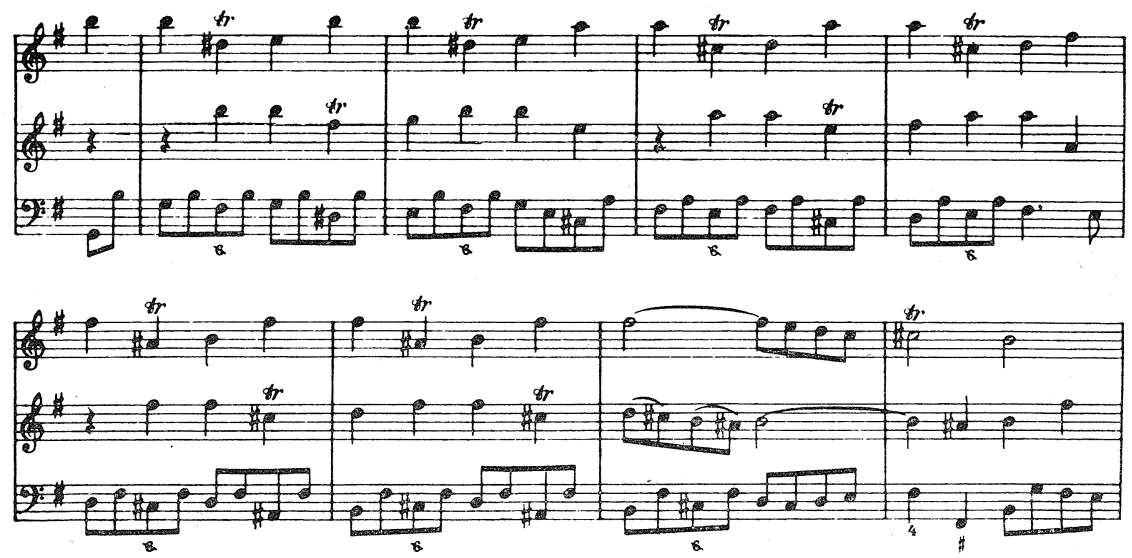

ziert. Man sieht, daß es sich eigentlich um kein neues Thema handelt; trotzdem wird ein Kontrast vor allem auf Grund des Augmentationsprinzips erreicht. Die Natur der beiden Themen gestattet den Schluß, daß zu ihrer Differenzierung auch die unterschiedliche Dynamik beitragen mußte, die den Interpreten anvertraut war: Nach den zeitgenössischen Interpretationsmanieren wurde das erste Thema (Notenbeispiel 15) wahrscheinlich forte, das zweite Thema (Notenbeispiel 16) piano vorgetragen. Die melodische Linie wird durch Triller gelockert, die nach eingebürgerten Usancen von oben, d.h. ohne verzierende Nebentöne, Mordente oder andere melodische Schlußverzierungen gespielt wurden. ${ }^{49}$

Auf dem manchmal sicher unbewußt beschrittenen Weg nach neuem Ausdruck gelangt Fernando dall'Abaco zu gegliederten Strukturen. Er unterscheidet das erste und zweite Thema durch die Art der Ausarbeitung, die Polyphonie kämpft mit der Homophonie. Im Schlußsatz seiner Violinsonate op. 4 Nr.3 (Notenbeispiel 17) ${ }^{50}$ expo-

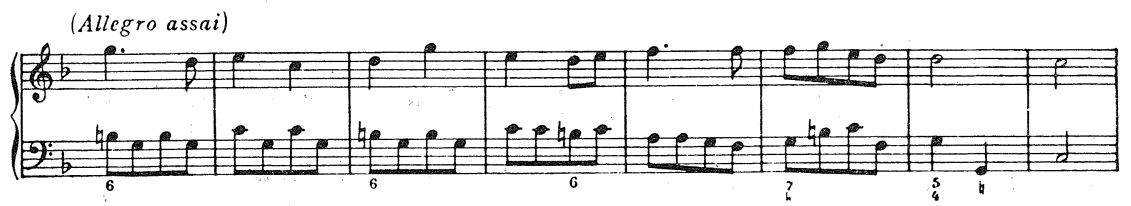

niert der Komponist das zweite Thema in homophoner Technik, wodurch er zwar einen Kontrast erreicht (sei es auch noch ohne

48 Bücken, 16. divers.

49 Die Aufführungspraxis der melodischen Verzierungen war damals ${ }^{50}$ Bücken, 17. 
prägnante Unterscheidung des melodischen Materials), aber auch eine Temporetardierung nicht vermeidet.

Allgemein betrachtet, streben die italienischen Komponisten vor 1740 nach einer Umbildung des alten barocken Sonatengebildes, ohne daß es ihnen noch gelingt, den echten Kontrast mit Hilfe eines selbständigen zweiten Themas zu schaffen. Einen durchdringenden Erfolg auf dem Weg zum zweiten Thema verzeichnet der hervorragende Vertreter der neapolitanischen Cembaloschule Domenico Scarlatti (1685-1757) in seinen »Essercizi«, die später aus pragmatischen Gründen "Sonaten" genannt wurden. ${ }^{51}$ Diese Bezeichnung gebührt vielleicht nur jenen Kompositionen aus Scarlattis Zyklus, in denen der Grundriß der klassischen Sonate mit klar gegliederten Abschnitten (Exposition, Durchführung und Reprise) erscheint. ${ }^{52}$ Diese Form ist allerdings noch recht unregelmäßig gefügt. In der Exposition begegnen wir meist zwei »Kontrast «-Themen, ${ }^{53}$ mit denen der Komponist in der Durchführung verschiedenartig verfährt: er modifiziert sie, kehrt sie um, behilft sich mit der Sequenztechnik, manchmal versucht er sie sogar neu zu entwickeln. Interessanterweise wird auch in der Reprise noch keine Ausgeglichenheit erzielt. Vor allem fehlt der Antritt des ersten Themas, das doch an verschiedenen Stellen der Exposition erscheint. Natürlich sind die klassischen Stilaspekte bei Domenico Scarlatti noch nachsichtig anzuwenden, handelt es sich doch um einen typischen Autor der Übergangszeit, von dem man nicht die volle "Reife des Herbstes« verlangen kann, obwohl er manche Züge des klassischen Stils nicht nur andeutet sondern schon ausprägt. Das zweite Thema hat sich bei ihm allerdings noch nicht völlig individualisiert, was bei Kompositionen um das Jahr 1740 nicht überrascht. Noch immer hängt es am barocken Kompositionsprinzip, das die kontrapunktische Linearität als bestimmenden Faktor der Musik ansieht. Dieses Prinzip hat Domenico Scarlatti nicht voll überwunden, trotzdem er seine Kompositionen um das modische und neue Element der Kontrasthaftigkeit bereichert und damit den barocken Kanon von der Einheit und Konzentration aller Ausdrucks- und Bauelemente verletzt, die den strengen Regeln der kontrapunktischen Arbeit unterlagen. Seine Themen werden noch immer von technischen Blickpunkten beherrscht, während doch schon in wenigen Jahren das musikalische Thema von einem neuen Dynamismus erfüllt sein sollte, dem sich Kompositionstechnik und Form unterordnen mußten. Der Themendualismus ist beispielsweise in Scarlattis bekanntner Cembalosonate d-Moll (Notenbeispiel 18) deutlich zu erkennen. Es ist als hätte der Komponist im zweiten Sonatenthema (vergl. die dritte Doppelzeile, Takt 2 u.f.) plötzlich die Fesseln der barocken Tradition gebrochen: seine Tonsprache ist hier bereits galant, und unterscheidet sich von der Exposition des ersten Themas zu Satzbeginn, das noch in barocker

\footnotetext{
51 Vgl. Keller, 38.

52 Bücken, daselbst.

53 Das Kontrastthema ist hier nicht im klassischen Sinne gemeint.
} 

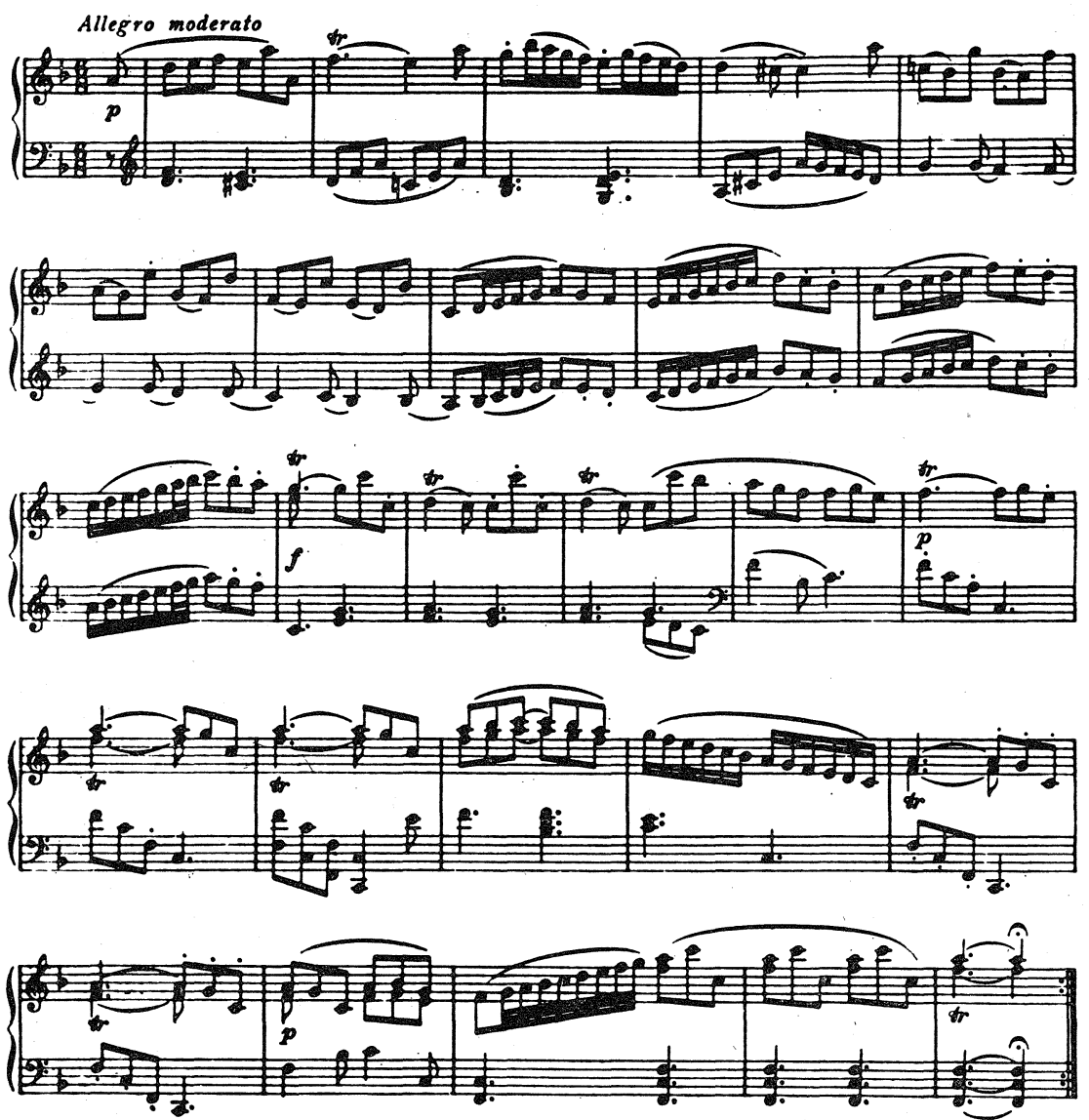

Technik, mit häufigen Imitationen in der linken Hand, behandelt wird. Das zweite Thema kontrastiert mit dem ersten einerseits in der Kompositionstechnik (die Homophonie siegt allmählich, obwohl man auch Spuren von Imitationen in den Stimmen der linken Hand entdeckt), anderseits in der Art und Weise, wie das Prinzip der wiederholten kurzen Abschnitte, ein bereits ausgesprochen klassisches Prinzip, zur Geltung kommt. Und trotzdem schwankt der Komponist noch (unterbewußt?) zwischen der alten und neuen Technik. Lassen sich doch beide Themen auf einen gemeinsamen Nenner bringen, weil der Themenkopf (vergl. 3 Doppelzeile, Takt 2 und 3) aus einem Teil des ersten Thema abgeleitet ist (vergl. 1. Doppelzeile, Takt 2). Die Achtelsprünge im zweiten Thema (3. Doppelzeile, 2. Hälfte des zweiten Taktes usw.) lassen sich wieder aus dem Kopf des ersten Themas ableiten (vergl.1. Doppelzeile, 1. Takt). Schon diese analytischen Bemerkungen berechtigen uns zur Feststellung, daß das zweite Thema organisch aus dem ersten wächst, daß also zwischen ihnen eine innere Einheit waltet, obwohl sie an und für sich kontrastvoll 
wirken. Interessant ist in diesem Zusammenhang Bückens Gedanke, ${ }^{54}$ man könne trotz der Neuheit von Scarlattis musikalischen Themen in der Komposition markante Spuren barocker Verfahren bei der Entfaltung des 5.-7. Taktes des ersten Themas entdecken, aber auch Wechselbeziehungen zu Geist und Form der alten Suite. Doch gibt der Autor keine nähere Erläuterung. Wir vertreten die Ansicht, daß man die lineare Sequenzentechnik Domenico Scarlattis vom Aspekt der Entwicklung keineswegs abschätzig beurteilen darf. Sie hat ja auch bei jüngeren Komponisten, bei der Generation der vierziger Jahre des 18. Jahrhunderts überlebt, wo sie häufig in den Durchführungen vorklassischer Symphonien und Sonaten erscheint. Auch Scarlattis Beziehung zum Suitentyp kann nicht überraschen, wenn man bedenkt, daß es um eine Zeit geht, in der Typ der sonata da camera und der Suite eigentlich noch lebensfähig war, da ihn die neuen Typen der klassischen Sonate und Symphonie noch lange nicht verdrängt hatten. Ernst Bücken hat auch nicht beachtet, daß man die Úberwindung der Melodik vom Giguentyp ${ }^{55}$ nicht ausschließlich als Beitrag Domenico Scarlattis bewerten kann. Schon Arcangelo Corelli schuf auf dem rhythmischen und formalen Grundriß der alten Gigue neue untraditionelle Gebilde. Im Concerto grosso G-dur lokkert er beispielsweise die Struktur dieses Finaltanzes und erfüllt sie mit einer durchaus tanzfremden Pastoralmelodik (Notenbeispiel 3), die sich Händels Pastorellen nähert. ${ }^{56}$ Der Ersatz der Gigue durch einen pastoralen Satz unter Beibehaltung der rhythmischen Tanzstruktur ist im Hochbarock im großen und ganzen nichts Außergewöhnliches. Typische Belege dafür bieten die allerdings nur stichprobenweise ausgewählten Beispiele aus Werken Antonio Vivaldis (gest. 1743?) ${ }^{57}$ und Georg Friedrich Händels (1685-1759). ${ }^{58}$

Wir haben bereits erwähnt, daß Domenico Scarlatti der echte Meister einer Übergangsperiode war. Sein Stil ist eroberungslustig, wächst aber trotzdem aus der Tradition. In Scarlatti reichen einander Vergangenheit und Zukunft die Hand. Wir haben Merkmale seines Schaffens verfolgt, die eine Brücke zu den klassischen Verfahren schlagen, und uns dabei vorwiegend auf architektonisch bedeutsame Komponenten seines Stils eingestellt. Bisher wurde aber noch nicht gesagt, daß Scarlatti auch Ausdrucksverfahren des Barocks mit expressiven Elementen der Klassik verschmilzt. Interessanterweise schlägt der Komponist manchmal sozusagen aus heiterem Himmel leidenschaftlich bewegte Saiten an, die sich den üblichen Praktiken entziehen. Hier reicht er jenen großen Meistern die Hand, die in Augenblicken des emotionellen Aufflammens Kompositionsflächen schaffen, welche den gewohnten Ausdruckshorizont

54 Bücken, 18.

55 Bücken, 19.

56 Corelli, Taschenpartitur, 141 n. Vgl. oben.

57 Vgl. z. B. den Finalsatz der Sonate A-Dur (in: Hohe Schule des Violinspiels, Bd. I, Leipzig, undatiert; revidiert von Ferdinand David).

58 Sonate g-moll für Violine und basso continuo. 
überschreiten: J.S. Bach in seinen philosophisch meditativen Adagien, G. F. Händel in den Begleitrezitativen seiner Opern und Oratorien, L. v. Beethoven in den letzten Streichquartetten. Domenico Scarlatti gesellt sich würdig zu diesen Meistern, die an empfindsam tiefen Stellen die Sprache des Herzens reden, ohne die Regeln des Zeitstils zu beachten. Ein Abschnitt aus Scarlattis sogenannter Sonate D-Dur (Notenbeispiel 19) ${ }^{59}$ läßt deutlich erkennen, wie dieser Kom-

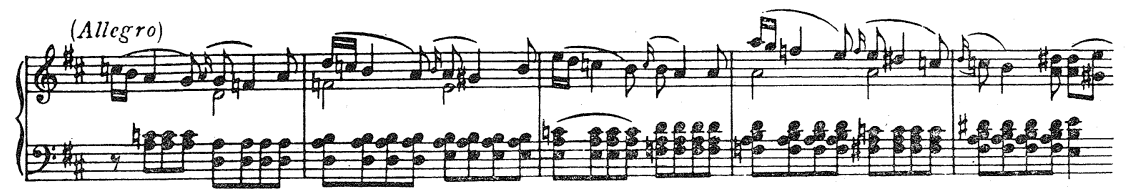

ponist den dramatischen, reich modulierten und harmonisch kühnen Ausdruck des Kommenden ahnt und vorwegnimmt. Das sind schon Takte, die den neuen, den »empfindsamen« Stil begrüßen ...

Im Abschnitt über die opera buffa haben wir hervorgehoben, daß Giovanni Battista Pergolesi in seiner "La serva padrona " bestimmte Kompositionsverfahren der Klassik anwendet. Diese Stilvorwegnahme wird in Pergolesis kammermusikalischem Schaffen besonders deutlich. Der Komponist hat sich hier fast aller schwerfällig feierlicher Regeln des Barocks entledigt, er schreibt einen klaren, transparenten, oft homophonen Satz. Seine Triosonaten sind eines der Fundamente der galanten Musik. Pergolesi übertrifft in dieser Hinsicht auch seinen großen Rivalen Nicolo Porpora (1686-1768), der noch allzusehr der Vergangenheit verpflichtet war. Nur in Por-
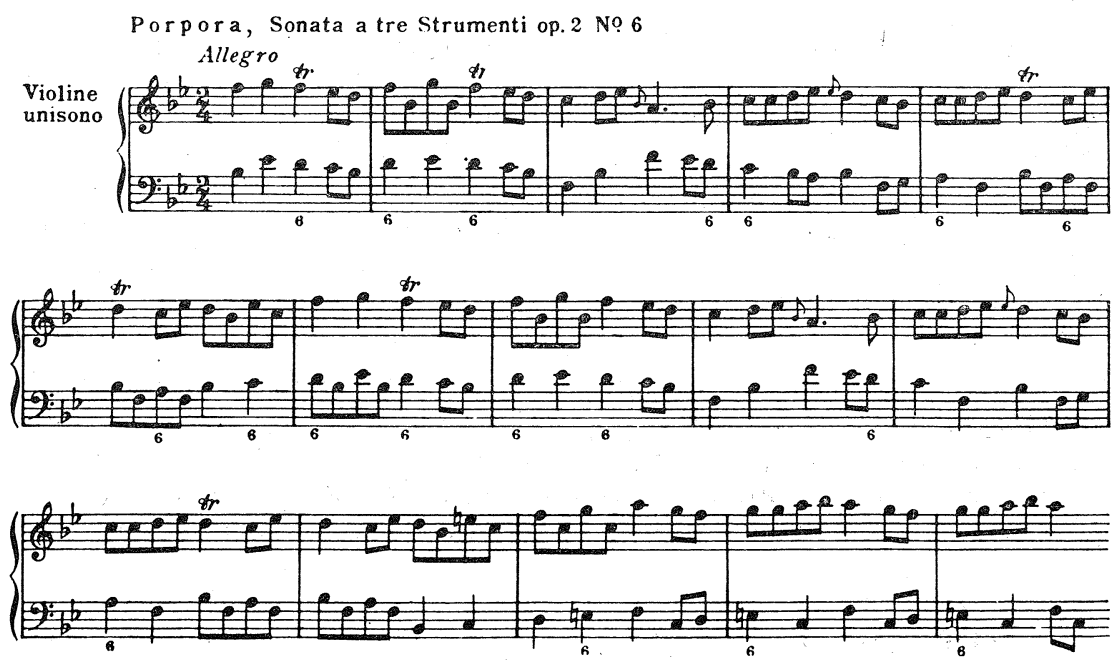

${ }^{59}$ Bücken, 19. 
poras Kammertrios aus dem Jahr 1736 hört man einen transparenteren Ausdruck und eine frischere Invention, sonst lassen seine Kompositionen kaum neue Prinzipien erkennen. ${ }^{60}$ Die Sonate à tre instrumenti, op. 2 Nr.6, B-Dur, bringt zwar im ersten Satz eine lebendige Melodie (Notenbeispiel 20), ${ }^{61}$ aber die Exposition ist $\mathrm{zu}$ statisch und unpersönlich. Im Vergleich mit Pergolesi ist Porpora entschieden weniger "galant«. Pergolesis Melodik ist freier und küh-
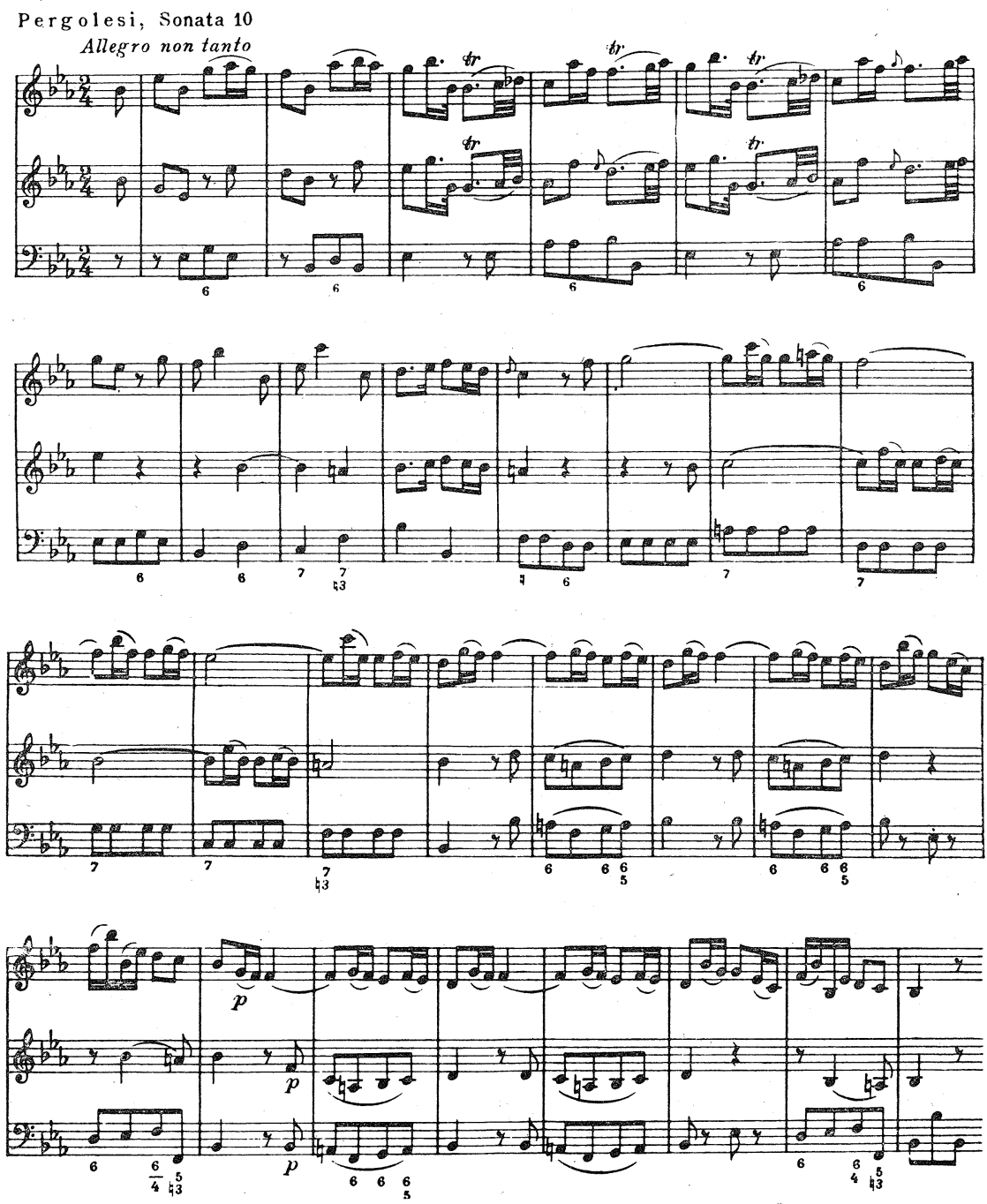

60) Bücken, 19-23.

61 „Denn die Aufänge des neuen Formprinzips der galanten gegliederten Rhytmik zeigen sich bei Porpora noch nicht.« (Bücken, 23.) 
ner, sie hat sich vom barock-monothematischen Prinzip befreit, wie das Beispiel aus dem ersten Satz der 10. Sonate Es-Dur (Notenbeispiel 21) beweist. ${ }^{62}$ Das zweite Thema (Takt 12 u.f.) wirkt ganz selbständig, obwohl es mit dem ersten Thema zusammenhängt: man beachte das melodische Sechzehntelgefälle (Takt $13 \mathrm{u}$.a. Stellen), das unwillkührlich an den "Komplimentier«-Typ der Quartette Joseph Haydns erinnert. ${ }^{63}$

Die Bedeutung von Pergolesis Kammermusik im Kodifikationsprozeß des vorklassischen Stils ist nicht $\mathrm{zu}$ übersehen. Von der Form aus betrachtet, haben diese Kompositionen zwar noch nicht das andere Ufer erreicht, zeichnen aber im ganzen als mächtiger geistiger Impuls die neue Zeit vor. Ihr Ausdruck ist maßvoll, sie unterdrücken die komplizierte Stimmführung und rechnen schon mit einer neuen Expressivität der Partitur, die der Individualisierung der Instrumente entspringt. In Pergolesis Kammermusik wird der zarte, graziöse Ausdruck des galanten Kammerstils geboren, der dann von dem italienischen Milieu in die großen Adelsresidenzen Europas ausstrahlen sollte. Dieser Stil ist von Kantabilität förmlich gesättigt: sie erscheint nicht nur in den langsamen - und das ist besonders bemerkenswert - sondern auch in den Allegrosätzen, die im Barock noch allzu sehr von kontrapunktischen Regeln gefesselt waren, um einen kantabilen Ausdruck zu gestatten. Pergolesi hatte damit einen neuen Stilbereich betreten, in dem das Melodiöse die Herrschaft antreten sollte. ${ }^{64}$

Ein wichtiges Glied in der Entwicklung der Instrumentalmusik sind die Werke Giovanni Battista Sammartinis (1701-1775), eines gebürtigen Mailänders, auf dessen Bedeutung der italienische Musikwissenschaftler Fausto Torrefranca als erster hingewiesen hat. ${ }^{65}$ Es scheint allerdings, als sei das Epitheton "Musikrevolutionär", das Torrefranca diesem Komponisten verlieh, etwas übertrieben. Auch mit Ernst Bückens Meinung, man könne Sammartinis Bedeutung mit der geschichtlichen Leistung Richard Wagners ivergleichen, ${ }^{66}$ kann man kaum übereinstimmen. Sammartini und Wagner sind denn doch wohl inkommensurable Größen. Beiden ist bloß gemeinsam, daß sie am Ende einer Stilepoche stehen - Wagner als ragendes Monument der Spätromantik, Sammartini als einer der Erfüller des italienischen galanten Stils, dessen Schaffenszüge in mancher Hinsicht auf den »empfindsamen" Stil hinweisen. Die Ausdrucksmittel des galanten Stils, vor allem die Technik der »zerbröckelnden« Motivarbeit und konsequenten Symmetrisierung des musikalischen Gedankens, sind für ihn typisch. Trotzdem hat er eigentlich nur gemehrt und ausgeführt, was Pergolesi so genial entworfen hatte. Auf den »empfindsamen« Stil zielt beispielsweise die freiere Themenar-

\footnotetext{
62 Bücken, 24.

${ }^{63}$ Bücken, 24-25. Über J. Haydn vgl. Pečman III.

64 Näher über Pergolesi bei Bücken, 1.c.

65 Torrefranca I, Torrefranca II, Torrefanca III.

66 Bücken, 25.
} 
beit, die bei Sammartini schon nicht mehr auf der bloßen symmetrischen Entwicklung des Gedankens beruht, sondern eine Brücke zu den langen thematischen Bögen schlägt, die dann für Tartini charakteristisch werden.$^{67}$ Robert Sondheimer ${ }^{68}$ unterstreicht die entdeckerische Bedeutung Sammartinis auf dem Gebiet des Themendualismus, obwohl der Komponist eigentlich nur die vorhergegangene Entwicklung in technischer Hinsicht gekrönt hat. Sofern er zu einer markanten Unterscheidung der beiden Themen gelangt, wirken sie tatsächlich kontrastvoll. Es ist aber noch immer möglich, sie auf einen gemeinsamen Nenner zu bringen. Wir sehen Sammartinis Bedeutung vor allem auf melodischem Gebiet, wo er mit stark vertieftem Ausdruck den Boden des galanten Stils verläßt (vergl. das Concertino für Flöte in G (Notenbeispiel 22), ${ }^{69}$ das weit entfernt von
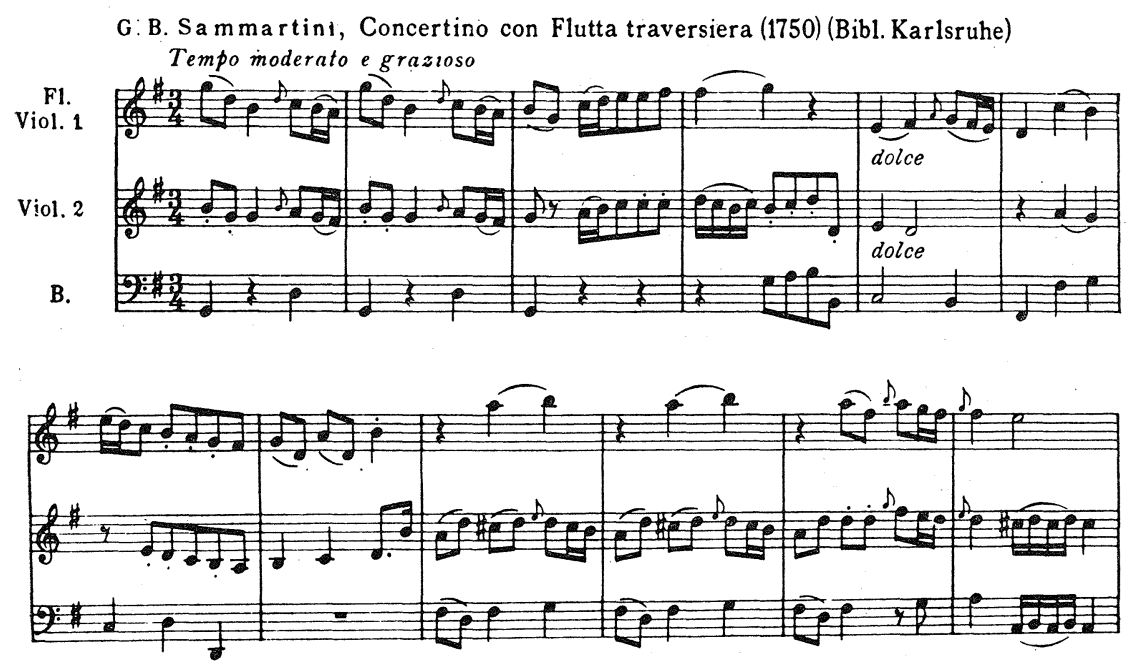

jenem "höfischen" Ausdruck ist, wie er zu Beginn des galanten Zeitalters herrschte). Die Tonsprache des Komponisten besitzt bereits die objektiven und vereinheitlichenden Charakterzüge der aufkommenden Klassik. Auf dem Boden des »empfindsamen" Stils bewegt sich Sammartini besonders in den langsamen Sätzen, z. B. im Larghetto des Es-Dur-Trios für zwei Violinen und Violoncello (Notenbeispiel 23). ${ }^{70} \mathrm{Im}$ Vergleich mit der vorhergegangenen Entwicklung ist hier der Ausdruck intensiver, die Melodik stärker gegliedert und harmonisch reicher; sie verwendet größere Intervalle. Die dominierende Stimme der ersten Violine, der die übrigen Stimmen untergeordnet sind, steht bereits in vollem Einklang mit den Grundsätzen der Klassik. Aus dem polyphonen Stil ist der homophone Stil ge-

67 Bücken, 26-27.

68 Sondheimer: s. die Angabe im Literaturverzeichnis.

69 Bücken, 29.

70 Daselbst. 
G. B. Sammartini, Trio Es Dur

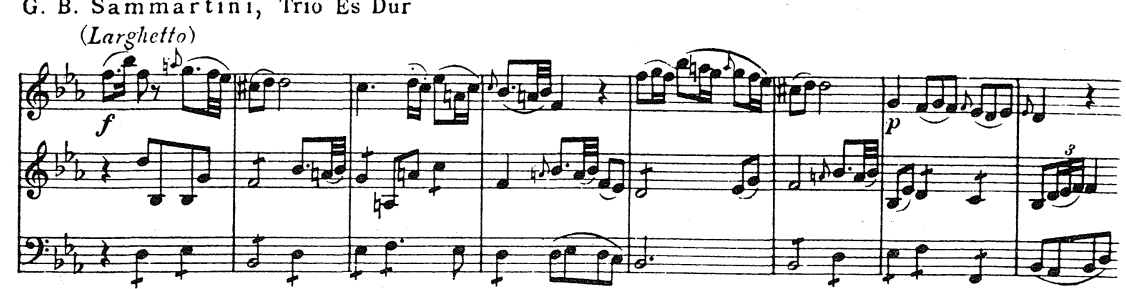

worden, die Linearität der Stimmen ist überwunden, die Melodie hat gesiegt...

Der Prozeß, der in den ersten drei Jahrzehnten des 18. Jahrhunderts in Italien einsetzte, trägt die typischen Züge des Úbergangs. Wie haben verfolgt, wie gerade in Italien alle wesentlichen Stilmerkmale entstanden sind, die für den sogenannten galanten Stil, das erste Entwicklungsstadium der Rokokomusik, charakteristisch waren. Gegen Ende der dreißiger Jahre des 18. Jahrhunderts setzen in der italienischen Musik jene Strukturverschiebungen ein, die den »empfindsamen" Stil der vierziger Jahre signalisieren. Die Genesis der galanten Elemente läßt sich bis zu Corelli zurückverfolgem.

Aus der Synthese galanter und empfindsamer Elemente wird der klassische Stil geboren, dessen Kulminieren man mit den Vertretern der Wiener Klassik, Haydn, Mozart und Beethoven, zu verbinden pflegt.

Den klassischen Stil haben Generationen geformt. Er entstand als Ergebnis vielfacher schöpferischer Anregungen, nicht nur in Italien. Allerdings besaßen die Impulse der italienischen Musik, die wir hier kurz behandelt haben, historische Priorität, wenn auch nicht im Sinne eines einzigartigen und dauernden Vorsprungs. Wir wollten dokumentieren, daß sich der herrschende Stil des Hochbarocks in der italienischen Musik am frühesten zu wandeln begann. Abermals ein Beweis, daß es unrichtig wäre, die einzelnen Stile als in sich abgeschlossene und übergangslose Epochen anzusehen, wenn es möglich war, daß schon die Epoche des italienischen Hochbarocks in ihrem Schoße galante (allgemeiner gesprochen: vorklassische) Ausdruckstendenzen getragen hat, die berufen waren, den Barockstil abzulösen. Aus Italien verbreiteten sich diese erstarkenden Tendenzen dann nach ganz Europa. Sie stützten und festigten die Wandlungen, die sich inzwischen - sozusagen simultan - im Rahmen der großen europäischen Musikkulturen Frankreichs und Deutschlands abgespielt hatten. Das Neue im Schaffen eines Couperin (1668 bis 1733), Daquin (1694-1772), Rameau (1683-1764) ${ }^{71}$ und anderer Meister der französischen Stilwende wächst vor allem aus dem Dialog mit dem erhabenen Stil Jean Baptist Lullys (1632-1687),

71 Wie wohl bekannt ist, war J. Ph. Rameau auch ein großer Kenner der Harmonie und Akustik. 
der opéra lyrique und opéra ballet. Mit Begeisterung begrüßen Rousseau und die Enzyklopädisten das Kommen der opera buffa; sie sehen in ihr den Ausweg, überschätzen sie oft, erfassen jedoch scharf, daß die Zukunft jenen gehört die sich vom traditionellen französischen Deklamationsstil befreien und den neuen Typ einer Melodik schafen werden, die aus homophonen Grundsätzen wächst. Deutschland, die Heimat des strengen Stils, besitzt in seinen musikalischen Denkern und Komponisten vom Typ eines Mattheson (1681-1864), Keiser (1674-1739), Telemann (1681-1767), Graupner (1683-1760), Händel (1685-1759) u. a. hervorragende Vertreter der neuen Stilwelle, die der Klassik den Boden vorbereitet. In diesem Zusammenhang machen wir besonders auf J. S. Bachs Söhne aufmerksam - es war vor allem Carl Philipp Emanuel (1714-1788), der als Vertreter der norddeutschen Schule ebenso tiefschürfend zur Kodifizierung des "empfindsamen" Stils beigetragen hat, wie beispielsweise die Komponisten der Wiener vorklassischen Schule Georg Matthias Monn (1717-1750) und Georg Christoph Wagenseil (1715-1777). Diese Entwicklungslinie strebt dann, von italienischen Anregungen gefördert, zu den Mannheimern.

Die gesamte Problematik des »empfindsamen« Stils, seine Verbreitung in Europa und sein Anschließen an die Hochklassik zu verfolgen, ist leider nicht mehr Gegenstand unserer Studie, die beweisen sollte, daß die italienische Musik in der Stilgärung an der Wende des Barocks zum ersten Stadium der Klassik eine wesentliche und entdeckerische Rolle gespielt hat. Damit hat sie sich richtungweisend in das Strombett der europäischen Musik ergossen und ihre Priorität bei der Behauptung klassischer Schaffensprinzipien unleugbar bewiesen. Die Entwicklung gab Italien recht. Es wurde zum Land des Fortschritts der Musik im 18. Jahrhundert, jenem Jahrhundert des Wetterleuchtens der neuzeitlichen Musikgeschichte.

(Übersetzung von Dr. Jan Gruna)

\section{LITERATURVERZEICHNIS}

BLUME, Friedrich: (I) Die Musik der Klassik, in: F. Blume, Syntagma musicologicum. Gesammelte Reden und Schriften. Kassel 1963 (herausgegeben von Martin Ruhnke). - (II) Die Musik des Barock, daselbst.

BÜCKEN, Ernst: Musik des Rokokos und der Klassik. WildparkPotsdam 1927.

BURNEY, Charles: A General History of Music. London 1789.

CHŁEDOWSKI, Casimir von: Das Italien des Rokoko. München 1935 (deutsch von Rosa Shapire). II. Ausgabe.

EGGEBRECHT, Hans Heinrich: Das Ausdrucksprinzip im musikalischen Sturm und Drang, in: Deutsche Vierteljahrschrift für Literaturgeschichte, J. 29/1955, 323-349.

FALYOLLE, Fr. J. M.: Notices sur Corelli, Tartini, Gaviniès, Pugnani et Viotti. Paris 1810. 
GERBER, Rudolf: Klassischer Stil in der Musik, in: Die Sammlung IV, Göttingen, November 1949, 652-665.

HAWKINS, John: The General History and Peculiar Character of the Works of Arcangelo Corelli, in: Universal Magazine of Knowledge and Pleasure. London 1777, Bd. LX, S. 171.

HOFFMANN-ERBRECHT, Lothar: Sturm und Drang in der deutschen Klaviermusik von 1753-1763, in: Die Musikforschung X, 1957, 466 bis 499 .

KELLER, Hermann: Domenico Scarlatti. Leipzig 1957.

MARCELLO, Benedetto: Il teatro alla moda ossia metodo sicuro e facile par la bene comporre ed esseguire la opera in musica. Venedig 1720 (?). Neu erschienen mit Vorwort und Anmerkungen von Andrea D'Angeli im J. 1927 (ohne Angabe des Erscheinungsortes).

PAUMGARTNER, Bernhard: Corelli Arcangelo, in: MGG II, 1952, Spalte 1668-1679.

PEČMAN, Rudolf: (I) Corellis Concerti grossi als Vorboten des Klassizismus, in: Sborník prací filosofické fakulty brněnské university XVII, Brno 1968, Serie H, Nr. 3, 29-42. - (II) Josef Mysliveček und sein Opernepilog. Brno 1970 (Opera Universitatis Purkynianae Brunensis, Bd. 164). - (III) Joseph Haydn - tvůrce klavírního tria (Joseph Haydn - Schöpfer des Klaviertrios), in: Koncertní život (Praha) 1959, Aprilnummer. (IV) Výrazové prostř̌edky neapolské vážné opery (Ausdrucksmittel der neapolitanischen opera seria). Brno 1970.

PINCHERLE, Marc: Corelli. Paris 1933.

ROLLAND, Romain: Metastasio als Vorläufer Glucks, in R. Rolland, Musikalische Reise ins Land der Vergangenheit. Frankfurt a. M. 1921, 147 bis 163 (deutsch von L. Arro).

SCHERING, Arnold: Geschichte des Instrumentalkonzerts. Leipzig 1903. Heft 2.

SONDHEIMER, Robert: G. B. Sammartini, in: ZfMw, Jg. 1920/21,

TORCHI, Luigi: La musica instromentale in Italia nei secoli XVI, XVII e XVIII, in: RMI 1901.

TORREFRANCA, Fausto: (I) La creazione della sonata drammatica moderna, in: RMI XVII. - (II) La lotta per l'egemonia musicale nel settecento, in: RMI XXIV. - (III) Le origini della sinfonia, in: RMI XX-XXII.

VATIELLI, Francesco: Il Corelli e i maestri bolognesi del suo tempo, in: Arte e vita musicale a Bologna, Bd. I, Bologna 1927.

WASIELEWSKI, Wilhelm Josef von: (I) Die Violine und ihre Meister. Leipzig 1927 (bearbeitet und ergänzt von Waldemar von Wasielewski). VII. Ausgabe. - (II) Geschichte der Instrumentalmusik im 16. Jahrhundert. Leipzig 1878.

WOEHL, Waldemar: Vorwort zur Herausgabe von Corellis Concerti grossi. Leipzig 1937 (Taschenpartitur, Edition Peters, Verlagsnr. 11362)

\section{POVZETEK}

Novejša muzikološka literatura pojmuje rokoko kot izrazito prehodni stil, ki sledi baroku in pripravlja visoko klasiko. Rokoko se razvija v dveh fazah: galantni in ekspresivni. Medtem ko poteka prva še paralelno s poznim barokom in doseže kulminacijo okoli leta 1740, je druga poznejša in se krije $\mathrm{z}$ obdobjem razcveta predklasične simfonije. Ne glede na to ju ni mogoče med seboj strogo ločiti in se bolj ali manj 
prepletata. Podobno kot $\mathrm{v}$ likovni umetnosti je iskati začetke rokokoja v Italiji in ne v Franciji.

Znaki galantnega stila so $\mathrm{v}$ okviru italijanskega poznega baroka sprva najbolj razločni na področju instrumentalne glasbe in se kažejo zlasti v strukturi melodije. Kot poznobaročni skladatelj je že postopoma utiral pot novi glasbeni miselnosti A. Corelli, čigar Concerti grossi so $\mathrm{v}$ tej zvezi zanimivi prav $\mathrm{z}$ melodičnega aspekta. Medtem, ko se pojavlja v počasnih stavkih Corellijevih Concertov tip pastoralne tematike, ki pravzaprav ne pripada več historičnemu območju baroka, najdemo v nekaterih hitrih stavkih že primere takoimenovane raketne teme, ki je sicer značilna za simfonično literaturo predklasičnega obdobja. Razen tega pri Corelliju ni prezreti pojavljanja melodičnega periodiziranja in določenega nakazovanja tematskega dualizma in izpeljavanja teme.

Vsaj posredno je pripravljala novo glasbeno epoho tudi napolitanska opera seria. Doslej še ni bilo dovolj poudarjeno, da je prav ta kodificirala »eterični« način instrumentacije, ki se nagiblje $\mathrm{k}$ liričnosti. Posamezni instrumenti opernega orkestra postanejo postopoma samostojni in vsak od njih je nosilec specifičnega izraza. Prav tako ni pri skladateljih opere serie kot so A. Scarlatti, L. Vinci, L. Leo in G. B. Pergolesi prezreti strastnih recitativov secco, $\mathrm{v}$ katerih je že latentno prisotna melodia continuata, katere dovršitelj je N. Jomelli. Važno je tudi, da v operi serii recitativ prevzema ariozni značaj, zaradi česar se meja med recitativom in arijo zabriše.

Da je imela pri stilnem presnavljanju eminentno vlogo opera buffa, je splošno znano dejstvo. V njej najdemo princip klasičnega členjenja melodije, melodiko, ki operira s pogostnim ponavljanjem kratkih period in odsekòv in je jasna in pregledna. Tukaj se je rodil tudi tipični buffo brio, ki je pozneje postal eden spoznavnih znakov klasične glasbene govorice. V Pergolesijevi "La serva padrona" pa se pojavi kot važen nov gradbeni element kratek motiv, ki prepaja celotno opero in ga skladatelj obravnava v smislu motivičnega izpeljevanja.

$\mathrm{Na}$ splošno teže italijanski komponisti pred letom 1740 za preoblikovanjem sonate, ne da bi jim uspelo ustvariti pravi kontrast s pomočjo samostojne druge teme. Prodoren uspeh na poti $\mathrm{k}$ tej je dosegel Domenico Scarlatti, v čigar sonatah srečamo že večkrat po dve temi. Scarlatti je še tipičen skladatelj prehodnega obdobja, čeprav je pri njem marsikatera poteza klasičnega stila ne le nakazana, ampak že izdelana. Obe temi njegovih sonatnih stavkov delujeta sami po sebi kontrastno, kljub temu pa še nista povsem individualizirani in jih nekako lahko spravimo na skupni imenovalec. Pri Scarlattiju naletimo tudi na poteze ekspresivnega stila. Nekatere njegove skladbe nas presenetijo $\mathrm{s}$ svojim strastnim nemirom.

Klasicistični kompozicijski postopki so na komornem področju posebno razločni pri Pergolesiju. Kot $\mathrm{v}$ operi buffi se Pergolesi tudi tu osvobodi težine baroka in ustvarja jasne in pogosto homofonske kompozicije. Njegov stil je takorekoč nasičen s kantabilnostjo, in to enako v počasnih kot hitrih stavkih.

Poleg Scarlattija in Pergolesija je važen člen $\mathrm{v}$ razvoju italijanske instrumentalne glasbe obravnavanega obdobja še Giovanni Battista Sammartini, za katerega je tipična tehnika razdrobljenega motivičnega dela in konsekventna simetričnost glasbenih misli. Na področje ekspresivnega stila je Sammartini segel posebno v počasnih stavkih. V takšnih primerih je izraz intenzivnejši, melodija močneje členjena in harmonsko bogatejša. 
Spremembe, ki najavljajo ekspresivni stil, so se začele pojavljati $\mathbf{v}$ italijanski glasbi proti koncu 30 -ih let 18. stoletja. Iz sinteze galantnega in ekspresivnega stila pa je nastal klasicizem, ki je dosegel kulminacijo s Haydnom, Mozartom in Beethovnom. Ta stil so pripravljale in oblikovale generacije. Nastal je kot rezultat mnogih ustvarjalnih spodbud, ki so prihajale ne le iz Italije, ampak tudi iz drugih dežel. Ne glede na to pa ni tajiti dejstva, da imajo pri pripravljanju klasičnega stila historično prioriteto impulzi italijanske glasbe. Iz Italije so se nove tendence razširile po vsej Evropi in podprle in okrepile spremembe, ki so se že medtem izvršile v okviru velikih glasbenih kultur Nemčije in Francije. 